\title{
Current Standards Landscape for Smart Manufacturing Systems
}

\author{
Yan Lu \\ KC Morris \\ Simon Frechette
}

This publication is available free of charge from:

http://dx.doi.org/10.6028/NIST.IR.8107

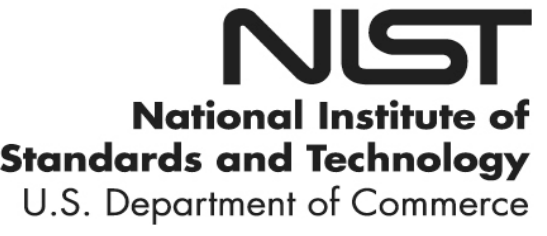




\title{
Current Standards Landscape for Smart Manufacturing Systems
}

\author{
Yan Lu \\ KC Morris \\ Simon Frechette \\ Systems integration Division \\ Engineering Laboratory
}

This publication is available free of charge from:

http://dx.doi.org/10.6028/NIST.IR.8107

February 2016

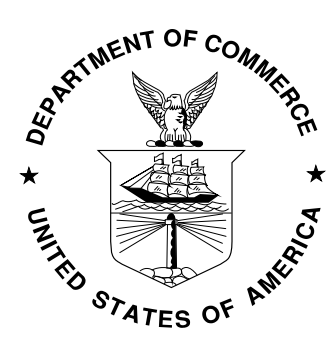

U.S. Department of Commerce Penny Pritzker, Secretary 


\begin{abstract}
Today's manufacturers face ever-increasing demands of variability-greater customization, smaller lot sizes, sudden supply-chain changes and disruptions. Successful manufacturers will have to choose and incorporate technologies that help them quickly adapt to rapid change and to elevate product quality while optimizing use of energy and resources. These technologies form the core of an emerging, information-centric, Smart Manufacturing System that maximizes the flow and re-use of data throughout the enterprise. The ability of disparate systems, however, to exchange, understand, and exploit product, production, and business data rests critically on information standards. This report provides a review of the body of pertinent standards-a standards landscape-upon which future smart manufacturing systems will rely. This landscape comprises integration standards within and across three manufacturing lifecycle dimensions: product, production system, and business. We discuss opportunities and challenges for new standards, and present emerging activities addressing these opportunities. This report will allow manufacturing practitioners to better understand those standards useful to integration of smart manufacturing technologies.
\end{abstract}

\title{
Disclaimer
}

Certain commercial systems are identified in this paper. Such identification does not imply recommendation or endorsement by NIST; nor does it imply that the products identified are necessarily the best available for the purpose. Further, any opinions, findings, conclusions, or recommendations expressed in this material are those of the authors and do not necessarily reflect the views of NIST or any other supporting U.S. government or corporate organizations. 


\section{CONTENTS}

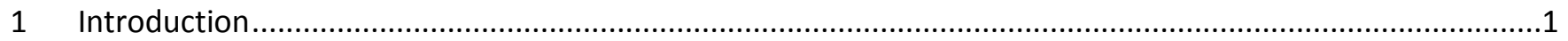

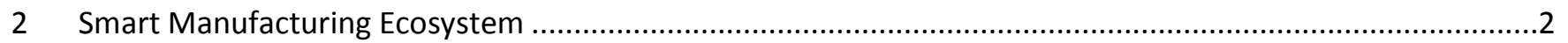

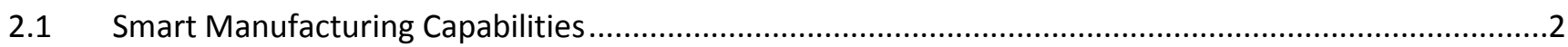

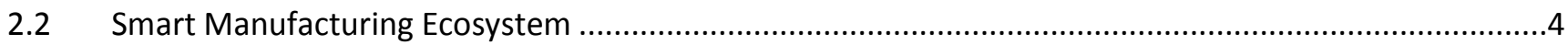

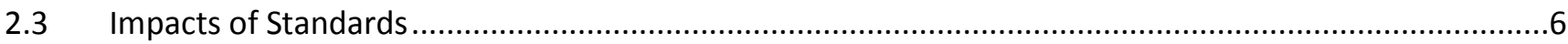

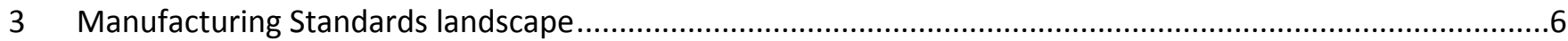

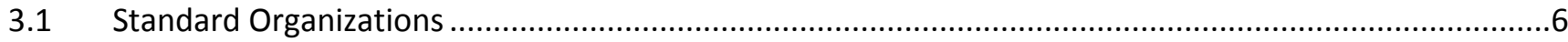

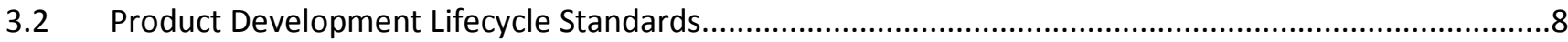

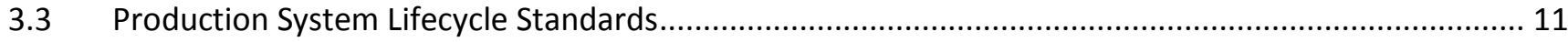

3.4 Business Cycle for Supply Chain Management............................................................................. 16

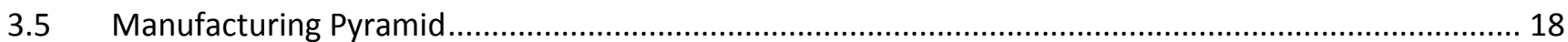

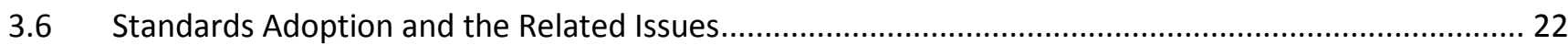

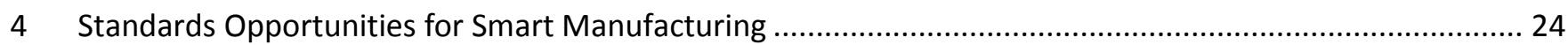

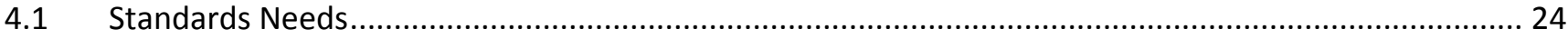

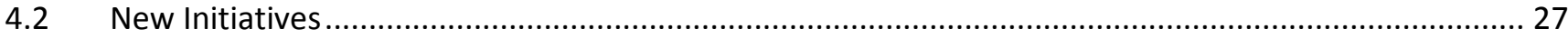

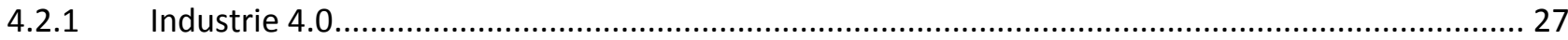

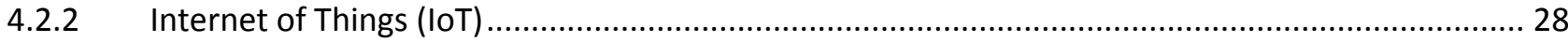

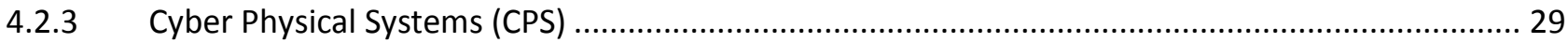

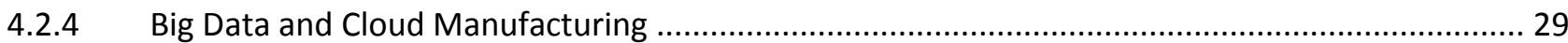

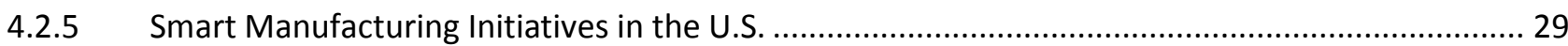

4.2.6 SDO Smart Manufacturing Related Activities............................................................................. 30

4.2.7 Sustainable Manufacturing Standards ................................................................................. 30

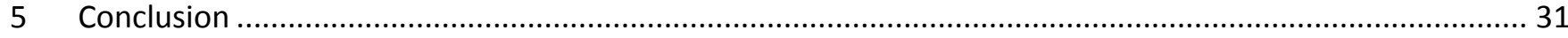

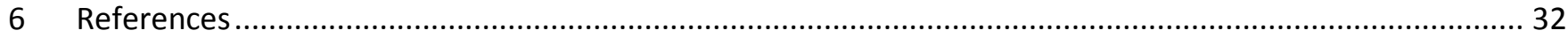




\section{INTRODUCTION}

A manufacturer's sustainable competitiveness depends on its capabilities with respect to cost, delivery, flexibility, and quality [1]. Smart Manufacturing Systems (SMS) attempt to maximize those capabilities by using advanced technologies that promote rapid flow and widespread use of digital information within and between manufacturing systems[2][3][4]. SMS are driving unprecedented gains in production agility, quality, and efficiency across U.S. manufacturers, improving long-term competitiveness. Specifically, SMS use information and communication technologies along with intelligent software applications to

1. Optimize the use of labor, material, and energy to produce customized, high-quality products for ontime delivery.

2. Quickly respond to changes in market demands and supply chains.

Smart manufacturing, different from other technology-based manufacturing paradigms, defines a vision of next-generation manufacturing with enhanced capabilities. It is built on emerging information and communication technologies and enabled by combining features of earlier manufacturing paradigms. Table 1 shows the relationship between SMS and previous manufacturing paradigms.

Table 1: Smart Manufacturing and other manufacturing paradigms ${ }^{1,2,3,4,5}$ and 6

Smart Manufacturing
Characteristics
- Digitization of every part of a
manufacturing enterprise with
interoperability and enhanced
productivity
Connected devices and
distributed intelligence for real
time control and flexible
production of small batch
products
Collaborative supply chain
management with fast
responsiveness to market
changes and supplying chain
disruption
Integrated and optimal decision
making for energy and resource
efficiency
Advanced sensors and big data
analytics through product
lifecycle to achieve fast
innovation cycle

Other Manufacturing Paradigms

Lean Manufacturing

- Emphasis on utilizing a set of "tools" that assist in the identification and steady elimination of all kinds of waste in a manufacturing system ${ }^{1}$

Flexible Manufacturing

- utilizing an integrated system of manufacturing machine modules and material handling equipment under computer control to produce products with changed volume, process and types ${ }^{2}$

\section{Sustainable Manufacturing}

- creating products with minimal negative environmental impacts while conserving energy and natural resources and enhancing human safety ${ }^{3}$.

\section{Digital Manufacturing}

- using digital technology through product lifecycle to improve product, process, and enterprise performance and reduce the time and cost of manufacturing ${ }^{4}$

\section{Cloud Manufacturing}

- a form of decentralized and networked manufacturing based on cloud computing and service-oriented architecture (SOA) $)^{5}$.

\section{Intelligent Manufacturing}

- implementing artificial intelligence based intelligent production that can automatically adapt to changing environments and varying proc ess requirements, with minimal intervention from human ${ }^{6}$.

\section{Holonic Manufacturing}

- applying agents to a dynamic and decentralized manufacturing process, so that changes can be made dynamically and continuously?

\section{Agile Manufacturing}

- utilizing effective processes, tools, and training to enable

manufacturing systems to respond quickly to customer needs and market changes while still controlling costs and qualitys.

\section{Enabling Technology}

Process leveling; work flow optimization; real-time monitoring and visualization

Modularized design; interoperability; service oriented architecture

Advance materials; sustainable processes metrics and measurement, monitoring and control

3D modeling; model based engineering product lifecycle management

Cloud Computing, IoT, virtualization, service-oriented technologies, and advanced data analytics

Artificial intelligence ; Advanced Sensing and control; optimization; knowledge management

Multi-agent systems; decentralized control; model based reasoning and planning

Collaborative engineering, supply chain management, product life cycle management

\footnotetext{
${ }^{1}$ Strategos-International. Toyota Production System and Lean Manufacturing, http://www.strategosinc.com/toyota_production.htm

${ }^{2}$ Flexible and reconfigurable manufacturing systems paradigms, Int J Flex Manuf Syst (2006) 17:261-276 DOI 10.1007/s10696-006-9028-7

${ }^{3}$ Glossary of Sustainable Manufacturing Terms, EPA, http://archive.epa.gov/sustainablemanufacturing/web/html/glossary.html

${ }^{4}$ DOE-FOA-0001263 Manufacturing innovation institute for smart manufacturing: advanced sensors, controls, platforms, and modeling for manufacturing.

${ }^{5}$ Cloud-Based Manufacturing: Old Wine in New Bottles? , Proceedings of the 47th CIRP Conference on Manufacturing Systems

${ }^{6}$ http://www.astri.org/technologies/initiatives/intelligent-manufaturing
} 
In 2014 in the United States, the President's Council of Advisors on Science and Technology (PCAST) issued a report that identified three top-priority transformative manufacturing technologies: Advanced Sensing, Control, and Platforms for Manufacturing; Visualization, Informatics and Digital Manufacturing Technologies; and Advanced Materials Manufacturing [5]. The first two of the technologies enhance the manufacturer's ability to respond to information quickly and efficiently. They, in turn, rely on the effective information flow and system responsiveness that only standards can provide. The PCAST further noted that standards "spur the adoption of new technologies, products and manufacturing methods. Standards allow a more dynamic and competitive marketplace, without hampering the opportunity to differentiate. Development and adoption of standards reduce the risks for enterprises developing solutions and for those implementing them, accelerating adoption of new manufactured products and manufacturing methods."

Standards are the building blocks that provide for repeatable processes and the composition of different technological solutions to achieve a robust end result. Standards come in many varieties and forms. Standards.gov [6] and OMB Circular A-119 [46] describe, in some detail, the variety of forms standards can take. The standards that we will discuss are primarily "voluntary consensus standards." This means they are set by a standards organization based on the consensus of the partners who will be using them. In addition, these types of standards are enforced by voluntary compliance. Such standards are designed to open new market opportunities to their users. The standards supporting SMS range from those for information technology and communication through those that govern enterprises and supply chains.

This paper presents an SMS standards' landscape based on a definition of a smart-manufacturing ecosystem that encompasses three dimensions - product, production systems, and enterprise (business) systems. The landscape associates standards with the lifecycle phases in each dimension. Section 2 presents key capabilities and the manufacturing ecosystem as the convergence of the three different lifecycle perspectives in operational manufacturing systems. It also identifies areas where the integration of functions within and across these dimensions will result in systems that are more effective. Section 3 describes the landscape in terms of key standards' organizations working in the area, types of standards in each of the three dimensions, and the manufacturing pyramid where the dimensions intersect. Finally, we discuss areas of opportunity for future standards in terms of the smart manufacturing capabilities.

\section{SMART MANUFACTURING ECOSYSTEM}

Standards are fundamental for enabling SMS. Different standards contribute in different ways to enabling the capabilities of smart manufacturing systems. To generate an SMS landscape, we identify the standards as within scope based on whether a standard contributes to a capability, and analyze where, when, and for what purpose the standard is used. This section defines the key capabilities and presents a visualization of a smart manufacturing ecosystem. The following section presents the standards landscape for the ecosystem.

\subsection{SMART MANUfacturing CAPABILITIES}

Significant and positive relationships exist between manufacturing strategies and corporate competitive strategies [47]. To achieve corporate competitive goals, manufacturing systems should be developed with capabilities aligned to a firm's competitive strategy, which usually consists of cost control and differentiation strategies of quality, delivery, innovation, service, and environmentally sustainable production. We classify key SMS-enabling capabilities into four categories including productivity, agility, quality, and sustainability (These characteristics are discussed in more detail in [14].) Table 2 shows a mapping of SMS capabilities to corporate competitive strategies. 
To analyze the role of existing manufacturing standards, we summarize the key SMS capabilities as follows:

Productivity: Manufacturing productivity is defined as the ratio of production output to inputs used in the production process [89]. Productivity can be broken down further to labor productivity and material and energy efficiency. As production sizes increase, typically productivity increases; however, for SMS for which customization is a hallmark, productivity measures may need to be adjusted to be more inclusive of responsiveness to customer demand.

Agility: Agility is defined as "the capability of surviving and prospering in a competitive environment of continuous and unpredictable change by reacting quickly and effectively to changing markets, driven by customer-designed products and services" [7]. Critical to the success of agile manufacturing are enabling technologies such as model-based engineering, supply chain integration, and flexible production systems with distributed intelligence. Traditional metrics to measure agility include On Time Delivery to Commit, Time to Make Changeovers, Engineering Change Order Cycle Time, and Rate of New Product Introduction [8]. New measures could include Delay Due to Supply Chain Change.

Table 2: Key Capabilities for Smart Manufacturing System

\begin{tabular}{|c|c|c|c|}
\hline $\begin{array}{l}\text { Corporate } \\
\text { Competitive } \\
\text { Strategy }\end{array}$ & $\begin{array}{l}\text { SMS Key } \\
\text { Capability }\end{array}$ & $\begin{array}{l}\text { Capability } \\
\text { Decomposition }\end{array}$ & Performance Metrics \\
\hline \multirow[t]{4}{*}{ Cost Control } & \multirow[t]{4}{*}{ Productivity } & Throughput & $\begin{array}{l}\text { Products being produced on a machine, line, unit, or plant over } \\
\text { a specified period of time }\end{array}$ \\
\hline & & $\mathrm{OEE}$ & $\begin{array}{l}\text { Overall Equipment Effectiveness - a multiplier of Availability } \\
\text { x Performance x Quality }\end{array}$ \\
\hline & & Material/Energy efficiency & $\begin{array}{l}\text { Material/Energy (electricity, steam, oil, gas, etc.) required to } \\
\text { produce a specific unit or volume of production }\end{array}$ \\
\hline & & Labor productivity & Worker hours per unit of production \\
\hline \multirow{10}{*}{ Differentiation } & \multirow[t]{3}{*}{ Agility } & Response to changes & $\begin{array}{l}\text { Time to Make Changeovers, Rate of New Product } \\
\text { Introduction, Engineering Change Order Cycle Time }\end{array}$ \\
\hline & & $\begin{array}{l}\text { On-Time Delivery to } \\
\text { Commit }\end{array}$ & $\begin{array}{l}\text { The percentage of time that manufacturing delivers a } \\
\text { completed product on the schedule }\end{array}$ \\
\hline & & Resilience to faults & Downtime in Proportion to Operating Time \\
\hline & \multirow[t]{4}{*}{ Quality } & Product quality & $\begin{array}{l}\text { Yield, Customer Rejects/Returns, and Material } \\
\text { Authorizations/Returns }\end{array}$ \\
\hline & & Innovation & Product innovativeness \\
\hline & & Variety & $\begin{array}{l}\text { Variety/product family; Options Per Product; Personalization } \\
\text { options }\end{array}$ \\
\hline & & Customer service & Customer reviews on services \\
\hline & \multirow[t]{3}{*}{ Sustainability } & Product & $\begin{array}{l}\text { Recyclability, Energy Efficiency, Durability, } \\
\text { Remanufacturability }\end{array}$ \\
\hline & & Process & Primary energy use; Greenhouse gas emission \\
\hline & & Logistics & Transportation fuel usage; Refrigeration energy usage \\
\hline
\end{tabular}

Quality: Traditional quality measures reflect how well finished products meet design specifications. In addition, for SMS, quality also includes measures of product innovation and customization. Traditional quality metrics include Yield, Customer Rejects/Returns, and Material Authorizations/Returns [8]. New quality measurement indicators for innovativeness and variety/product family and options/product to measure personalization degree are needed. 
Sustainability: While time and cost as measures of productivity have been the traditional drivers for manufacturing, sustainability has taken on more importance. Measurement science for manufacturing sustainability is not as mature as for time and cost and is an active area of research [18] [19]. As productivity and agility of manufacturing systems increases, the necessity for better understanding and controlling the sustainability-related impacts of those systems increases. Manufacturing sustainability is defined in terms of environmental impact (such as energy and natural resources), safety and well-being of employees, and economic viability [9].

\subsection{SMART MANUFACTURING ECOSYSTEM}

The Smart Manufacturing Ecosystem encompasses a broad scope of systems in the manufacturing business including production, management, design, and engineering functions. Figure 1 illustrates three dimensions of concern that are manifest in SMS. Each dimension-product (green), production system (blue), and business (orange)-is shown within its own lifecycle. The product lifecycle is concerned with the information flows and controls beginning at the early product design stage and continuing through to the end-of-life of the product. The production system lifecycle focuses on the design, deployment, operation and decommissioning of an entire production facility including its systems. The business cycle addresses the functions of supplier and customer interactions. Each of these dimensions comes into play in the vertical integration of machines, plants, and enterprise systems in what we call the Manufacturing Pyramid (Figure 5). The integration of manufacturing software applications along each dimension helps to enable advanced controls at the shop floor and optimal decision-making at the plant and enterprise. The combination of these perspectives and the systems that support them make up the ecosystem for manufacturing software systems. Details of the lifecycle of the three dimensions, as well as the Manufacturing Pyramid, will be described in Section 3.

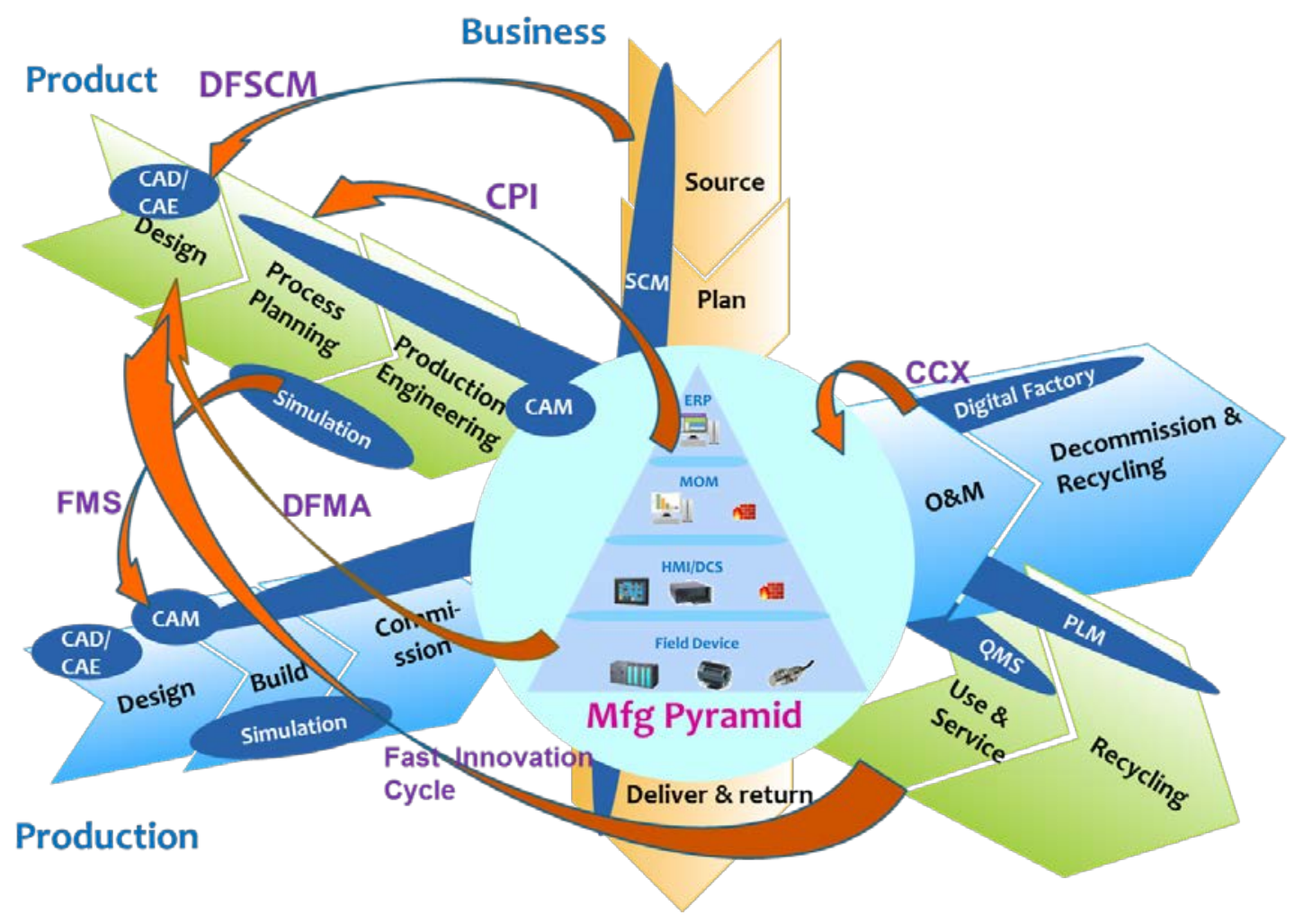

Figure 1. Smart Manufacturing Ecosystem 
Historically, these dimensions have been dealt with as silos of concern. Indeed, integration along even one of these dimensions is a non-trivial challenge and is being actively worked on. We have observed that organizations that were formed to integrate single dimensions of this ecosystem are expanding in scope to address the digital thread across the dimensions (orange arrows in Figure 1). Paradigms such as continuous process improvement (CPI), flexible manufacturing (FMS), and design for manufacturing and assembly (DFMA) rely on information exchange between the dimensions as indicated in Figure 1. Tighter integration within and across the three dimensions will result in faster product-innovation cycles, more efficient supply chains, and more flexibility in production systems. The combination of these allows for optimal control of the automation and decision-making needed to make high quality, highly customized goods in tight synchronization with the demand for these goods [10].

Essentially, it is the seamless integrations within and across SMS dimensions and the manufacturing pyramid that lead to SMS capabilities. Table 3 shows the integration technologies highlighted in Figure 1 and the SMS capabilities supported by them.

Table 3: SMS Ecosystem and Capability Mapping

\begin{tabular}{|c|c|c|c|}
\hline & Description & Information Flow & $\begin{array}{l}\text { Key Capabilities } \\
\text { Supported }\end{array}$ \\
\hline PLM & $\begin{array}{l}\text { Product life cycle management - is the process of } \\
\text { managing the entire lifecycle of a product from } \\
\text { inception, through engineering design and } \\
\text { manufacture, to service and disposal of manufactured } \\
\text { products }\end{array}$ & $\begin{array}{l}\text { Bi-directional information flow } \\
\text { through product and production } \\
\text { system lifecycle }\end{array}$ & $\begin{array}{l}\text { Quality, Agility and } \\
\text { Sustainability }\end{array}$ \\
\hline $\mathrm{SCM}$ & $\begin{array}{l}\text { Supplying chain management - The management of } \\
\text { upstream and downstream value-added flows of } \\
\text { materials, final goods, and related information among } \\
\text { suppliers, company, resellers, and final consumers. }\end{array}$ & $\begin{array}{l}\text { Bi-directional information flow among } \\
\text { supply chain stakeholders - } \\
\text { manufacturers, customers, suppliers } \\
\text { and distributors }\end{array}$ & $\begin{array}{l}\text { Agility, Quality, } \\
\text { Productivity }\end{array}$ \\
\hline DFSCM & $\begin{array}{l}\text { Design for Supply Chain Management - designing } \\
\text { products to take advantage of and strengthen supply } \\
\text { chain. }\end{array}$ & $\begin{array}{l}\text { Bi-directional information flow } \\
\text { between supply chain management } \\
\text { activities and design engineers } \\
\text { activities }\end{array}$ & Quality and Agility \\
\hline CPI & $\begin{array}{l}\text { Continuous process improvement - is the set of on- } \\
\text { going systems engineering and management activities } \\
\text { used to select, tailor, implement, and assess the } \\
\text { processes used to produce products. }\end{array}$ & $\begin{array}{l}\text { Information flow from run-time } \\
\text { manufacturing system to process } \\
\text { design activities }\end{array}$ & $\begin{array}{l}\text { Quality, Sustainability, } \\
\text { Productivity }\end{array}$ \\
\hline $\operatorname{ccx}$ & $\begin{array}{l}\text { Continuous Commissioning - ongoing process of } \\
\text { diagnosis, prognosis and performance improvement } \\
\text { of production systems }\end{array}$ & $\begin{array}{l}\text { Bi-directional Information between } \\
\text { production engineering activities and } \\
\text { production operation activities }\end{array}$ & $\begin{array}{l}\text { Productivity, Agility, } \\
\text { Sustainability and } \\
\text { Quality }\end{array}$ \\
\hline DFMA & $\begin{array}{l}\text { Design for Manufacturing and Assembly - the design for } \\
\text { ease of manufacture of the parts the design of the } \\
\text { product for ease of assembly. }\end{array}$ & $\begin{array}{l}\text { Information flow from production } \\
\text { engineering, operation activities to } \\
\text { product design activities }\end{array}$ & Productivity and Agility \\
\hline FMS/RMS & $\begin{array}{l}\text { Flexible Manufacturing System/Reconfigurable } \\
\text { Manufacturing system - machines are flexible and can } \\
\text { be configured to produce changed volume or new } \\
\text { product types with or without changed process }\end{array}$ & $\begin{array}{l}\text { Information flow from product } \\
\text { engineering activities to production } \\
\text { engineering activities }\end{array}$ & Agility \\
\hline $\begin{array}{l}\text { Manufactur } \\
\text { ing Pyramid }\end{array}$ & $\begin{array}{l}\text { The hierarchical nature of existing manufacturing } \\
\text { systems illustrated by a three-level pyramid including } \\
\text { ERP, MoM and shop floor. }\end{array}$ & $\begin{array}{l}\text { Bi-directional flow among ERP, MoM } \\
\text { activities and control systems }\end{array}$ & $\begin{array}{l}\text { Quality, Agility, } \\
\text { Productivity and } \\
\text { Sustainability }\end{array}$ \\
\hline $\begin{array}{l}\text { Fast } \\
\text { Innovation } \\
\text { Cycle }\end{array}$ & $\begin{array}{l}\text { To improve New Product Introduction (NPI) Cycle by } \\
\text { anticipating trends through gathering data from } \\
\text { product usage and feeding it back into product } \\
\text { ideation }\end{array}$ & $\begin{array}{l}\text { Information flow from product use to } \\
\text { product design }\end{array}$ & Quality and Agility \\
\hline
\end{tabular}




\subsection{IMPACTS OF STANDARDS}

Standards are fundamental and valuable tools that can enable the adoption of technologies and innovations by business owners. Accordingly, they contribute to one or more SMS key capabilities. For example, on the product dimension, PLM standards contribute to both agility (by streamlining processes) and quality (by enabling the integration of different activities along the product and production system lifecycles). In the production system area, continuous commissioning (CCX) standards can improve machine performance and systems reliability to improve productivity, quality, and sustainability (through improved energy performance). Standards for electronic commerce such as the Open Applications Group Integration Specification (OAGIS) help streamline business processes between partners in the supply chain.

The next section presents a landscape of manufacturing standards on top of the SMS ecosystem where we see clearly existing manufacturing standards and how they can enhance SMS capabilities, if adopted.

\section{MANUFACTURING STANDARDS LANDSCAPE}

Existing manufacturing standards provide "how-to" instructions for designers, engineers, builders, operators, and decision makers to conduct disciplined activities within their domains. They also facilitate communication between stakeholders across domain borders, borders of the manufacturing system hierarchy, and between lifecycle phases. Today, numerous national, regional, and international standards development organizations (SDOs) set manufacturing industry standards. This section provides a review of the types of standards for each of the three lifecycle dimensions with a focus on those standards that specifically address manufacturing information content. While some national or regional standards are considered, more emphasis is placed on international standards. In many cases, local SDOs may have direct liaisons with international SDOs. First, we provide an overview of the standards development organizations and then we position the standards within the ecosystem. ${ }^{7}$

\subsection{STANDARD ORGANIZATIONS}

A completed standard is typically the result of one of several development processes. The more traditional of these is via a formally sanctioned SDO. These organizations facilitate consensus building and ensure that standards are openly available to organizations that wish to use them. In this category are both international standards bodies, such as ISO [20] IEC [30], ASME [21], and ASTM [22]; and national bodies including professional organizations, which define best practices for their practitioners. In the United States, ANSI [23] certifies professional organizations to create standards in areas of specialization.

The traditional consensus-building process used by SDOs can be quite time-consuming; as a result, other processes have emerged, including open source [24]. In the open-source process, a standard can come in the form of a specification describing the standard, a reference implementation of the standard, or both. These standards are often developed within a consortium, maintained collaboratively, and widely available to the public at large. Ownership of these standards remains a public trust of various sorts and they are open to interested participants. The licensing and governance models for the intellectual property contained in these standards vary greatly between projects. Open-source standards sometimes proceed to a more formal sanction by an SDO. An independent organization usually manages the open source process. Some vendor-driven

\footnotetext{
${ }^{7}$ In the interest of brevity, we do not provide references for every standard described. They are easily accessible through an Internet search.
} 
standardization communities have taken another approach whereby a vendor implementation of a proposed standard is selected to define the standard. The chosen implementation becomes the reference to which other vendors implement.

Multiple standards intended to work together are often defined as suites. Examples of this in the Information Technology (IT) world include the collection of standards from groups like WC3 [25] and IETF [26] that have aided the digital revolution. In the world of manufacturing, we find the ISO 10303 suite of standards (commonly known as STEP) for product data [27], the Quality Information Framework(QIF)[32] for streamlining quality testing capabilities, and the standards emerging from consortia such as the Open Application Group, Inc. (OAGi) for enterprise level applications [28]. These standards incorporate other, more fundamental, standards, e.g., the EXtensible Markup Language (XML) from W3C, and offer engineering and manufacturing content representation and interpretation. The Object Management Group (OMG) [38] also defines suites of standards that, for the most part, address underlying technologies rather than those specific to manufacturing. Some of these standards have become particularly useful for manufacturing application and are discussed later.

ISO and IEC are working on standards of significant importance to smart manufacturing. Within ISO, the technical committee on automation systems and integration (TC184) has two subcommittees (SC) that are of particular interest in our landscape: SC4 and SC5. SC4 focuses on industrial data standards - primarily those related to product data including ISO 10303. SC5 focuses on interoperability, integration, and architectures for automation applications. Both subcommittees have new standards for smart manufacturing in development.

IEC, which historically has served the electronics industry, has developed standards that have broader applicability beyond the electronics industry. For example, IEC TC 65 focuses on standards for industrial process control and automation and is active in addressing integration between product data and production processes. ISO/IEC Joint Technical Committee (JTC) 1 on information technology deals with a large number of standardization topics in IT for manufacturing systems including sensor and device networks and user interfaces. Consequently, these types of standards are also included in our landscape.

A number of consortia are developing standards and best practices in the SMS area including OAGi, MTConnect [29], ProSTEP iViP [81], OPC Foundation [31], DMSC [32], and MESA [33]. Standards and best practices from these organizations are sometimes proposed in ISO and IEC to facilitate broader dissemination and adoption. OAGi and MTConnect make standards freely available as open source for downloading to the public. PDES Inc., for example, is an industrial consortium that undertakes projects related to product data exchange for design. Their projects are driven by its members' specific needs for data integration standards. Results are fed into the ISO 10303 standards for product definition and others as appropriate. The work often addresses resolving issues surrounding the implementation of those standards. The OPC Foundation originally developed standards that allowed device providers to integrate their products into a Microsoft-based platform. OPC Foundation has since evolved into an independent standards organization with its own certification and testing program. Dimensional Metrology Standards Consortium (DMSC) [32] sets standards including QIF, which is fundamental for assuring that the entire quality-measurement process-consisting of product measurement design, planning, rules, resources, programming, results, and summary statistics-is fully integrated and traceable.

APICS [35], ASTM, MESA, IPC [79], and ISA [34] are industrial professional societies or trade associations working to advance the state-of-the-art in their fields. Their work includes standards, as well as educational and other activities. The APICS scope is supply chain and operations management. A part of APICS, known as the Supply Chain Council, produced a series of reference documents to provide guides on best practices for the 
supply chain industry. This rich set of information includes definitions for a wide range of performance metrics for manufacturing operations, many of which can be applied outside of the supply chain context. ASTM addresses manufacturing and materials, products and processes, systems, and services. MESA is concerned with the production level of Manufacturing Operations Management (MOM) or Manufacturing Executions Systems (MES) and the integration of information systems from the enterprise level into the manufacturing operation. IPC originated with the electronics industry, specifically focusing on printed circuit boards, but, as with many of the other organizations, its scope has expanded to address service and supply chain topics as well. ISA focuses on automation, specifically as applied to "engineering and technology to improve the management, safety, and cybersecurity of modern automation and control systems used across industry and critical infrastructure."[34] While each of these organizations brings a different perspective, their scopes intersect in our focus areas product, production system, and business information flows.

Other noteworthy standards come from more academically oriented professional societies, which typically are ANSI accredited. These include the standards from IEEE [37] and ASME.

\subsection{Product DeVelopment Lifecycle StandardS}

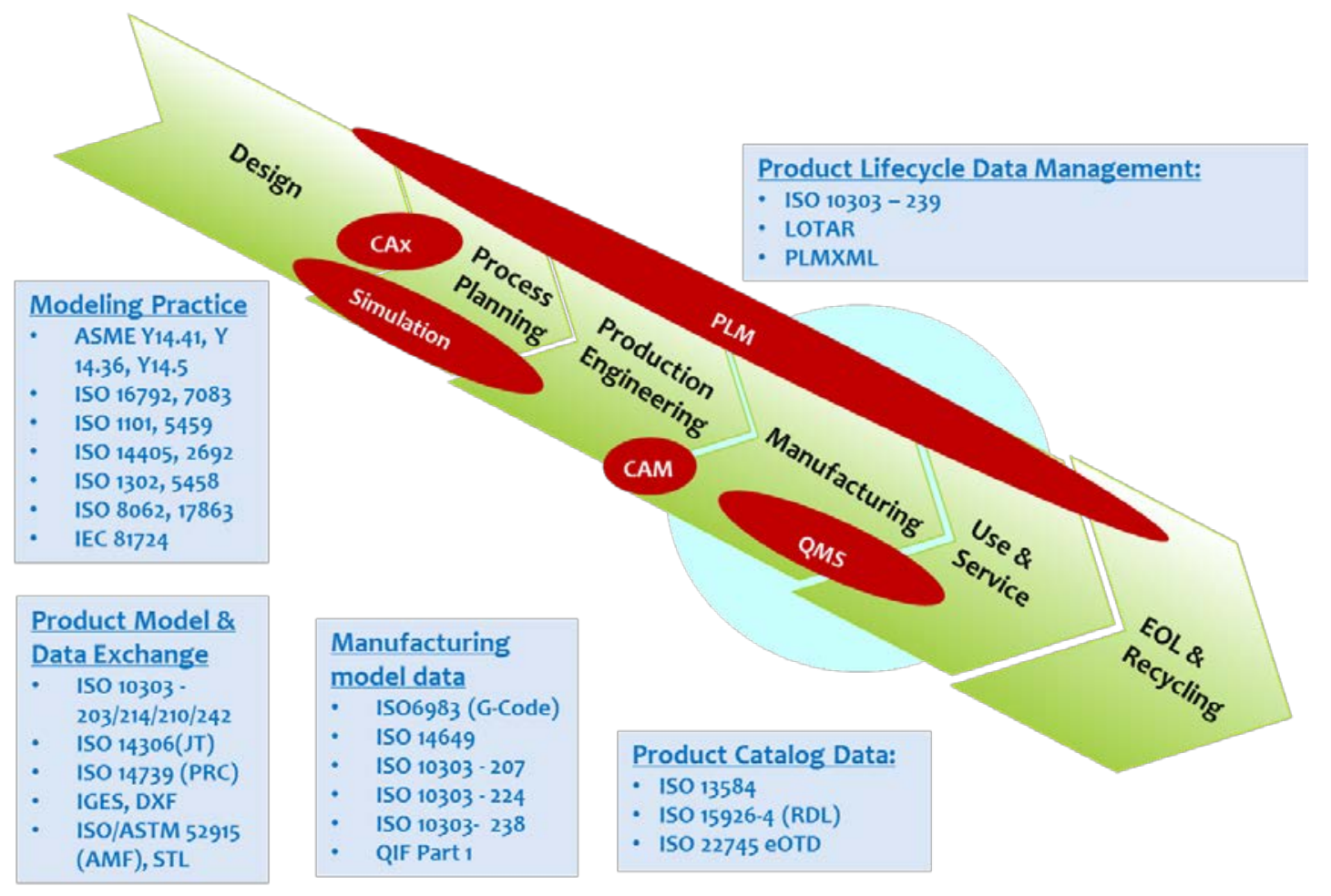

Figure 2. Standards along the Product Lifecycle

The product lifecycle in the context of the smart manufacturing ecosystem includes 6 phases as shown in Figure 2: Design, Process Planning, Production Engineering, Manufacturing, Use and Service, and End-of-Life and Recycling. The existing standards, particularly in the areas of Computer Aided Design (CAD), Computer Aided Manufacturing (CAM), and Computer Aided Technology (CAx) generally have greatly improved engineering efficiency [11]. In addition, these standards enhance modeling accuracy and reduce product innovation cycles, thus contributing directly to manufacturing system agility and product quality. Advancements in this area have resulted in a new product development paradigm known as model-based engineering or enterprise, or MBE [51]. 
Figure 2 also shows a set of select standards related to the product lifecycle phases. These standards are classified into five categories: Modeling Practice, Product Model and Data Exchange, Manufacturing Model Data, Product Category Data, and Product Lifecycle Data Management.

Modeling practice standards define digital product-definition data practices for both two-dimensional (2D) drawings and three-dimensional (3D) models. There are several standards available worldwide that define symbols and rules for dimensioning and tolerancing. The predominant standards are ASME (American Society of Mechanical Engineers) Y14.5 GD\&T (Geometric Dimensioning and Tolerancing) and International Organization for Standardization, ISO/TC 213 GPS (Geometrical Product Specification) with ISO/TC 10 Technical Product Documentation. The ISO (GPS) standards are typically address a single topic. The ASME Y14.5 standard combines a set of topics for GD\&T in one standards document. In addition to GD\&T, ASME Y14.36M and ISO 1302 are established standards for communicating surface texture control requirements and defining surface texture properties. The joint IEC/ISO standard 81714 defines graphical symbols for use in technical documentation of products. Table 4 lists selected modeling practice standards from ASME and ISO. There are also standards for specific manufacturing domains such as electronics product modeling practice including IPC-D-325 for printed boards, assemblies, and supporting drawings.

Table 4: Modeling Practice Standards

\begin{tabular}{|c|c|c|}
\hline SDOs & Standards & Description \\
\hline & ASME Y14.36 & Surface Texture Symbols \\
\hline \multirow[t]{2}{*}{ ASME } & ASME Y14.41 & Digital Product Definition Data Practices \\
\hline & ASME Y14.5 & Dimensioning and Tolerancing \\
\hline \multirow{3}{*}{ ISO TC 10} & ISO 16792 & Technical product documentation -- Digital product definition data practices \\
\hline & ISO 128 & Technical drawings -- General principles of presentation \\
\hline & ISO 7083 & $\begin{array}{l}\text { Technical drawings -- Symbols for geometrical tolerancing -- Proportions and } \\
\text { dimensions }\end{array}$ \\
\hline \multirow{8}{*}{$\begin{array}{l}\text { ISO TC } 213 \\
\text { Geometrical } \\
\text { Product } \\
\text { Specificatio } \\
\text { ns (GPS) }\end{array}$} & ISO 1101 & Geometrical tolerancing -- Tolerances of form, orientation, location and run-out \\
\hline & ISO 5459 & Geometrical tolerancing -- Datums and datum systems \\
\hline & ISO 14405 & Dimensional tolerancing \\
\hline & ISO 2692 & $\begin{array}{l}\text { Geometrical tolerancing -- Maximum material requirement (MMR), least } \\
\text { material requirement (LMR) and reciprocity requirement (RPR) }\end{array}$ \\
\hline & ISO 5458 & Geometrical tolerancing -- Positional and pattern tolerancing \\
\hline & ISO 1302 & Indication of surface texture in technical product documentation \\
\hline & ISO 8062 & Dimensional and geometrical tolerances for moulded parts \\
\hline & ISO 17863 & Tolerancing of moveable assemblies \\
\hline IEC/ISO & IEC/ISO 81714 & Design of graphical symbols for use in the technical documentation of products \\
\hline IPC & IPC-D-325 & $\begin{array}{l}\text { Documentation Requirements for Printed Boards, Assemblies and Support } \\
\text { Drawings }\end{array}$ \\
\hline
\end{tabular}


Product model and data exchange standards include ISO standards and de facto standards, as shown in Table 5. These standards capture the representation of product and engineering information to enable data exchange between CAD software from different vendors. STEP is unique in that it addresses a broader range of information than is needed for CAD representations. The STEP architecture includes underlying methods for the definition and exchange of data and an architecture for integrating the data definitions into implementable units, called Application Protocols (AP), where CAD information is connected to product structure, as well as a wide array of other engineering and lifecycle information elements. The most commonly implemented and used APs are 203 for aerospace, defense and AP 214 for automotive [52]. The most recent part of STEP to be released is AP 242 edition 2, titled "Managed Model Based 3D Engineering" [48][52]. This standard merges AP 203 and AP 214 and incorporates requirements for data exchange in the areas of model-based development, product data management (PDM), product and manufacturing information (PMI), and long-term archiving of digital data. AP 242 is complementary to other visualization exchange formats such as JT (ISO 14306) and PRC (ISO 14739). Another set of standards for product modeling is used in additive manufacturing areas. The Stereo Lithography (STL) file format is widely used for rapid prototyping, 3D printing and additive manufacturing. ISO 52915, Additive Manufacturing File Format (AMF), is an open standard proposed to describe color, materials, lattices, and constellations of a 3D object that allows more complex descriptions of products, beyond basic geometry.

Table 5: Product Model and Data Exchange Standards

\begin{tabular}{|c|c|}
\hline Standards & Description \\
\hline \multirow{5}{*}{$\begin{array}{l}\text { ISO } 10303- \\
203 / 214 / 210 / 212 / 242\end{array}$} & 203: Configuration controlled 3D designs of mechanical parts and assemblies - aerospace and defense \\
\hline & 214: Core data for automotive mechanical design processes \\
\hline & 210: CAD systems for printed circuit board \\
\hline & 212: CAD systems for electrical installation and cable harness \\
\hline & 242: specifies the application protocol for Managed model based $3 \mathrm{~d}$ engineering. \\
\hline ISO $14306(\mathrm{JT})$ & $\begin{array}{l}\text { A CAD file format described in ISO 14306:2012 is used primarily in industrial use cases as the means for } \\
\text { capturing and repurposing lightweight 3D product definition data. }\end{array}$ \\
\hline ISO $14739(\mathrm{PRC})$ & Document management -- 3D use of Product Representation Compact (PRC) format \\
\hline IGES & $\begin{array}{l}\text { An ASCII-based exchange format adopted by the American National Standards Institute (ANSI) since } \\
\text { 1976. All meaningful development of IGES stopped in } 1996 \text { at version 5.3. }\end{array}$ \\
\hline STL & $\begin{array}{l}\text { A de-facto file format describe only the surface geometry of a three-dimensional object for additive } \\
\text { manufacturing. }\end{array}$ \\
\hline $\begin{array}{l}\text { ISO/ASTM } 52915 \\
(\mathrm{AMF})\end{array}$ & $\begin{array}{l}\text { A new and open XML based standard developed as a replacement for STL format. AMF has many } \\
\text { additional features compared to the STL format, including curved patches, recursive subdivision, multiple } \\
\text { materials, graded materials, internal structures, material properties, colors, graphics, constellations, and } \\
\text { metadata support. }\end{array}$ \\
\hline
\end{tabular}

Manufacturing model data standards, in contrast to the product model standards that focus on product design, define the data needed to manufacture a product from a design (Table 6). ISO 6983, or G-Code, is the most widely used Numerical Control (NC) programming language. ISO 14649 was developed to overcome the problems of ISO 6983 by defining a data model to enable a link between manufacturing operations and the original CAD geometry data. STEP AP 238 is designed to extend ISO 14649 in order to integrate more tightly with product design definitions. It can exchange explicit toolpath descriptions along with part, stock, fixture geometry, tool descriptions, GD\&T, and PDM information. 
Table 6: Manufacturing Model Data Standards

\begin{tabular}{|l|l|}
\hline Standards & Description \\
\hline ISO 6983 (G-Code) & $\begin{array}{l}\text { Numerical control of machines -- Program format and definitions of address words. The most widely } \\
\text { used numerical control (NC) programming language }\end{array}$ \\
\hline ISO 14649 & $\begin{array}{l}\text { Standard that specifies the technology-specific machine tool description data elements needed as } \\
\text { process data for manufacturing and machine characteristics. }\end{array}$ \\
\hline ISO 10303-207/224/238 & 207 -Sheet metal die planning and design \\
\hline 224 - Mechanical product definition for process plans using machining features \\
\hline
\end{tabular}

Product catalog data standards support the description of particular instances of products or parts in a uniform, vendor-neutral way. Examples of product catalog data standards include ISO 13584, 15926-Part 4 and 22745. The first two of these focus on methods for catalog definition. ISO 13854 specifies the principles to be used for defining characterization classes of parts and properties of parts independent from any particular supplier-defined identification. ISO 22745 provides guidelines for the development of terminology for open technical dictionaries and inventory and catalog systems. In contrast, 15926 Part 4 represents a specific domain and defines the engineering terms required to design, build, and operate an oil and gas production facility.

Product lifecycle data management focuses on the needs of long-term retention and access to data consistently throughout the product lifecycle. The best-known product lifecycle data management standard is ISO 10303 AP239, also known as Product Life Cycle Support (PLCS). AP 239 is designed for the exchange of complex-product for life-long support, i.e., the information needed and created during the use and maintenance of products. PLM XML is an emerging open format from Siemens for facilitating PLM. PLM XML is designed as a lightweight, extensible, and flexible format for sharing product design and function data in a collaborative environment [53]. The related LOTAR (LOng Term Archiving and Retrieval) International Project has an even broader scope. The LOTAR focus is long-term access to digital product and technical information through the development of standards-based archival and retrieval mechanisms. The results of that effort are recommended practices on how standards can be applied to long-term archiving of products and associated design information.

\subsection{PROduction SYSTEM LIFECYCLE StANDARDS}

"Production systems" here refers to collections of machines, equipment, and auxiliary systems organized to create goods and services from various resources.[49] Most product-model and modeling-practice standards are applicable to production system development as well. However, as one of the most complex product systems that is intended to manufacture goods, production systems have a number of unique standards that are fundamental to achieving SMS. Production systems usually have a much longer lifecycle than the goods that they produce. Additionally, they need to be frequently reconfigured, and thus have unique needs with respect to their design. The unique SMS capabilities discussed here are made possible by automation standards for system control and maintenance. In this subsection, we focus on standards supporting complex system modeling, automation engineering, and operation and maintenance (O\&M) perspectives of production systems.

Typical lifecycle phases for a production system as shown in Figure 3 include Design, Build, Commission, O\&M, and Decommission. Production systems and facilities are typically designed to manufacture a family of products. The degree of manufacturing flexibility-how adaptive a production system is in responding to market and 
supply chain changes-is a key design decision that not only impacts cost but also influences the length of the production system lifecycle. The commissioning phase involves testing the entire production system, including equipment, plant and facility, and handing off the system for operation. The system is verified to function according to the design objectives and specifications. After commissioning, the production system enters O\&Ma steady state of tactical operations and strategic maintenance activities. When radical internal or external changes are introduced, for example, if the main subsystems crash or the targeted product group is phased out of the market, the life of the product system comes to an end. At this point, production permanently ceases or the system is recycled. The steady-state O\&M stage is typically the longest phase of a production system's lifecycle. During this period, production systems are managed to best transform material, energy, and labor into products. In this phase, adaptation planning, re-commissioning, and continuous commissioning are conducted to maintain and improve system performance and search for ways to reconfigure the system to adapt to changes in the market and supply chain.

Areas of standards that support production lifecycle activities include Production System Model Data and Practice, Production System Engineering, O\&M, and Production Lifecycle Management. Since the O\&M stage is the longest phase, the standards for O\&M and lifecycle management merit special attention. Specifically, standards supporting manufacturing operations are discussed in detail in the Manufacturing Pyramid subsection.

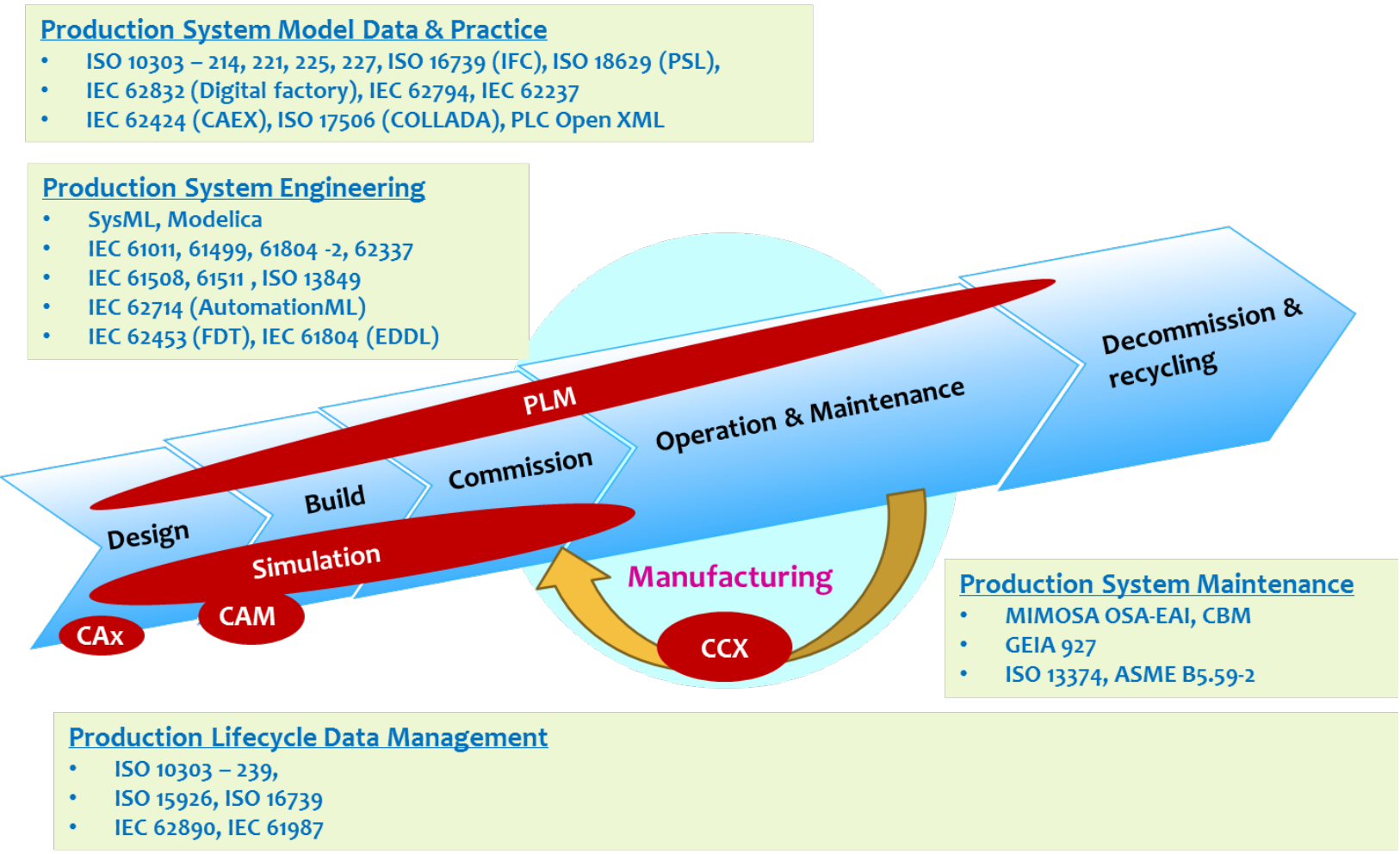

Figure 3. Standards for Production System Lifecycle 
Production system model data and practice standards provide information models for factory and production system design. They enhance information exchange among stakeholders, and enable virtual commissioning, which can improve manufacturing agility and reduce manufacturing cost. Besides CAx standards, several international standards specific to production system modeling and data exchange exist. The standards in this area can be classified into two domains as shown in Table 7: manufacturing resource and process, and building/facility modeling. ISO 10303 AP 214 has been shown to be able to represent different aspects of a manufacturing system in development [53]. ISO 10303 AP 221 defines functional data for, and schematic representation of, process plants. ISA 95 defines an equipment hierarchy model and models manufacturing processes [34]. ISO 18629 defines a Process Specification Language (PSL) aimed at identifying and formally defining and structuring the semantic concepts intrinsic to the capture and exchange of process information related to discrete manufacturing. IEC 62832(Digital Factory) defines a comprehensive network of digital models, methods, and tools to represent the basic elements and automation assets, as well as the behavior and relationships between these elements/assets. The digital factory concept includes five views of information: Construction (C), Function (F), Performance (P), Location (L) and Business (B). ISO 17506 defines an open standard for exchanging digital assets among various graphics software applications for plant geometry representation and kinetics simulation. The Core Manufacturing Simulation Data (CMSD) Information Model was developed by NIST and standardized by the Simulation Interoperability Standards Organization (SISO) to define a

Table 7: Production System Modeling and Practice Standards

\begin{tabular}{|c|c|c|}
\hline Domain & Standards & Description \\
\hline \multirow{11}{*}{$\begin{array}{l}\text { Manufacturing } \\
\text { Resource and } \\
\text { Process Domain }\end{array}$} & $\begin{array}{l}\text { ISO } 10303- \\
214 / 221\end{array}$ & $\begin{array}{l}\text { 214: Core data for automotive mechanical design processes to represent a manufacturing } \\
\text { system which is a part of factory design } \\
\text { 221-Functional data and schematic representation of process plants }\end{array}$ \\
\hline & ISA 95 & $\begin{array}{l}\text { Defines hierarchy models for a manufacturing enterprise and function/activity/object models } \\
\text { for Manufacturing Operations Management }\end{array}$ \\
\hline & IEC 62424 & Provides neutral data format that allows storage of hierarchical plant object information \\
\hline & ISO 18629 & $\begin{array}{l}\text { Process Specification Language developed by NIST is a set of logic terms used to } \\
\text { describe processes. }\end{array}$ \\
\hline & IEC 62832 & $\begin{array}{l}\text { Industrial-Process Measurement, Control and Automation-Reference Model for } \\
\text { Representation of Production Facilities (Digital Factory) }\end{array}$ \\
\hline & ISO 17506 & $\begin{array}{l}\text { COLLADA - defines an open standard XML schema for exchanging digital assets among } \\
\text { various graphics software applications }\end{array}$ \\
\hline & $\begin{array}{l}\text { PLC Open } \\
\text { XML }\end{array}$ & $\begin{array}{l}\text { The standard allows the representation of control logics for programmable Logic controllers } \\
\text { based on XML technologies }\end{array}$ \\
\hline & CMSD & Core manufacturing Simulation \\
\hline & IEC 62337 & $\begin{array}{l}\text { Commissioning of electrical, instrumentation and control systems in the process industry - } \\
\text { Specific phases and milestones. }\end{array}$ \\
\hline & ISO 15746 & $\begin{array}{l}\text { Defines information models for advanced process control and optimization capabilities for } \\
\text { manufacturing systems. }\end{array}$ \\
\hline & IEC 61987 & $\begin{array}{l}\text { Industrial-process measurement and control - Data structures and elements in process } \\
\text { equipment catalogues }\end{array}$ \\
\hline \multirow[t]{2}{*}{$\begin{array}{l}\text { Building/facility } \\
\text { Domain }\end{array}$} & $\begin{array}{l}\text { ISO } 10303- \\
225 / 227\end{array}$ & $\begin{array}{l}225 \text { - Building elements using explicit shape representation } \\
227 \text { - Plant spatial configuration }\end{array}$ \\
\hline & ISO 16739 & $\begin{array}{l}\text { Industry Foundation Class (IFC) - Building information modeling standard developed } \\
\text { by buildingSMART (formerly the International Alliance for Interoperability, IAI) to } \\
\text { facilitate interoperability in the architecture, engineering and construction (AEC) industry }\end{array}$ \\
\hline
\end{tabular}


data-interface specification for efficient exchange of manufacturing lifecycle data in a simulation environment. PLC Open XML provides standards to represent programmable logic control (PLC) including sequences of actions, internal behavior of objects, and Input/Output (IO) connections. IEC 62337 defines specific phases and milestones in the commissioning of electrical, instrumentation, and control systems in the process industry. IEC 61987 defines a standard to facilitate understanding of process measurement and control equipment descriptions when transferred from one party to another.

Production system engineering standards can interconnect engineering tools from different disciplines, e.g., system engineering, mechanical plant engineering, electrical design, process engineering, process control engineering, Human Machine Interface (HMI) development, PLC programming, and robotic programming. In the production system engineering category, there are several important standards playing critical roles in improving production system engineering efficiency, as shown in Table 8. While most of these standards serve very specific functions, two of them are fundamental methods, which underpin much of the work in production system engineering. The Systems Modeling Language (SysML) [38] from OMG is a general-purpose modeling language for systems engineering applications. It supports the specification, analysis, design, verification, and validation of a broad range of systems and systems-of-systems, and is particularly useful for large-scale projects such as production systems. Modelica [92] is an object-oriented, declarative, multi-domain modeling language. Modelica is widely used in applications that model complex physical systems and particularly to model the mechanical, electrical, electronic, hydraulic, thermal, control, electric power, or process-oriented subcomponents of production systems.

In the production system automation engineering area, IEC 61131 is a widely adopted standard for programmable controllers, including equipment requirements and tests, communication, functional safety, programming languages, and their implementation guidelines. Specifically, IEC 61131-3 is the most widely adopted standard defining the programming languages for PLCs, embedded controls, and industrial personal computers (PCs). IEC 61499 is an open standard for distributed control and automation, upon which entire applications can be built from Function Blocks (FB) with event triggers. This standard has not been accepted by industry, even though it is highly promoted by the academic community, because it does not provide a solid framework for the next generation of industrial automation systems [54]. IEC 61804 defines FB for process control. IEC 62714, AutomationML, interconnects engineering tools from different disciplines, e.g., mechanical plant engineering, electrical design, process engineering, process control engineering, $\mathrm{HMI}$ development, PLC programming, and robotic programming, etc. [12]. AutomationML incorporates different standards through strongly typed links across the formats including CAEX (IEC 62424) for properties and relations of objects in their hierarchical structure, COLLADA for Graphical attributes, and Kinematics and PLCopen XML for logic items. IEC also has a set of standards to model and configure production equipment, such as IEC 62453-2 for field device tool interface specification, and IEC 61804-3 specifying Electronic Device Description Language (EDDL). ISO 18828 is under development by ISO TC184/SC4 for standardized procedures for production systems engineering.

For production engineering practice, IEC 61508 is the international standard for electrical, electronic, and programmable electronic safety-related systems. It specifies requirements for ensuring that systems are designed, implemented, operated, and maintained to standards for safety integrity levels (SIL). IEC 61511 is a technical standard that specifies practices in the engineering of systems that ensure the safety of an industrial process through the use of instrumentation. This standard is process-industry specific within the framework of IEC 61508. ISO 13849 provides safety requirements and guidance on the principles for the design and integration of safety-related parts of control systems, including the design of software. 
Table 8: Production System Engineering standards

\begin{tabular}{|c|c|}
\hline Standard & Description \\
\hline SysML & $\begin{array}{l}\text { Systems Modeling Language (SysML) dialect of the Unified Modeling Language (UML) for systems } \\
\text { engineering applications owned by OMG. }\end{array}$ \\
\hline Modelica & $\begin{array}{l}\text { Modelica }{ }^{\circledR} \text { is a non-proprietary, object-oriented, equation based language to conveniently model complex } \\
\text { physical systems containing managed by Modelica Association }\end{array}$ \\
\hline IEC 61131 & An IEC standard for programmable controllers. \\
\hline IEC 61499 & $\begin{array}{l}\text { An open standard for distributed control and automation based on basic building blocks from which entire } \\
\text { applications may be built. }\end{array}$ \\
\hline IEC 61804 & $\begin{array}{l}\text { Function blocks (FB) for process control } \\
\text { Part 2: Specification of FB concept } \\
\text { Part 3: Electronic Device Description Language (EDDL) }\end{array}$ \\
\hline IEC 61508 & Functional safety of electrical/electronic/programmable electronic safety-related systems. \\
\hline IEC 61511 & Safety instrumented systems for the process industry sector ; \\
\hline ISO 13849 & Safety of machinery -- Safety-related parts of control systems \\
\hline IEC 62714 & Automation $\mathrm{ML}$ - Engineering data exchange format for use in industrial automation systems engineering. \\
\hline IEC 62453 & Field device tool (FDT) interface specification \\
\hline ISO 18828 & Standardized procedure for production systems engineering in development \\
\hline
\end{tabular}

Production lifecycle data management standards define general models of data integration, sharing, exchange, and hand-over for lifecycle support of production facilities. A selected set of important production lifecycle data management standards are shown in Table 9. A study of information modeling [53] found that ISO 10303 AP 239 (PLCS) has the most potential to model a manufacturing system for its lifecycle. However, guidance is needed regarding how to use PLCS for representing domain-specific objects such as machining centers [90]. ISO 15926 is the most widely used production lifecycle data management standard in the process industry. ISO $15926-1$ defines a class structure of various phenomena or occurrences that exist in time and space in that industry.

Table 9: Production lifecycle data management standards

\begin{tabular}{|l|l|}
\hline Standard & Description \\
\hline ISO 10303-239 & Product lifecycle support \\
\hline ISO 15926 & $\begin{array}{l}\text { Industrial automation systems and integration -- Integration of lifecycle data for process plants including } \\
\text { oil and gas production facilities }\end{array}$ \\
\hline ISO 16739 & $\begin{array}{l}\text { Industry Foundation Class (IFC) - Building information modeling standard developed to } \\
\text { facilitate interoperability in the architecture, engineering and construction (AEC) industry }\end{array}$ \\
\hline IEC 62890 & $\begin{array}{l}\text { Lifecycle management for systems and products used in industrial-process measurement, control and } \\
\text { automation }\end{array}$ \\
\hline
\end{tabular}


Due to the generic character of the PLCS data model in 15926, the 15926 standard defines a reference data model in Part 4 providing more useful entities for representing process plants. ISO 16739 defines a common data model for building lifecycle support that can be applied to manufacturing facilities. The emerging IEC 62890 defines standards for lifecycle management for systems and products used in industrial process measurement, control and automation.

O\&M standards define data processing, communication, and presentation standards for condition monitoring and diagnostics of machines, for maintaining the adequate performance of the system, and for searching ways to improve performance. Table 10 shows a selected set of O\&M standards. Standards supporting production O\&M include MIMOSA Open Systems Architecture for Enterprise Application Integration (OSA-EAI) specifications and condition-based maintenance (CBM) specifications, which are widely used in the Oil and Gas industry. ISO 13374 also defines data processing, communication, and presentation standards for condition monitoring and diagnostics of machines. The upcoming ASME B5.59-2 will address performance and capabilities of machine tools at any time in their lifecycles, e.g., during specification, after acceptance testing, or during operation. ASME B5.59-2 addresses only information related to the machine tool itself and does not include process-related information [53].

Table 10: Production System O\&M Standards

\begin{tabular}{|l|l|}
\hline Standard & Description \\
\hline ISO 13374 & $\begin{array}{l}\text { The standard establishes general guidelines for software specifications related to data processing, } \\
\text { communication, and presentation of machine condition monitoring and diagnostic information. }\end{array}$ \\
\hline $\begin{array}{l}\text { MIMOSA OSA- } \\
\text { CBM }\end{array}$ & $\begin{array}{l}\text { The Open System Architecture for Condition-Based Maintenance (OSA-CBM) specification is a standard } \\
\text { architecture for moving information in a condition-based maintenance system. }\end{array}$ \\
\hline $\begin{array}{l}\text { MIMOSA OSA - } \\
\text { EAI }\end{array}$ & $\begin{array}{l}\text { Open System Architecture for Enterprise Application Integration (OSA-EAI) specification provides an } \\
\text { information exchange standard to allow sharing information between enterprise systems and a relational } \\
\text { database model to allow storage of the same asset information. }\end{array}$ \\
\hline ASME B5.59.2M & $\begin{array}{l}\text { Information Technology for Machine Tools Part2 - Data Specification for Properties of Machine Tools for } \\
\text { Milling and Turning }\end{array}$ \\
\hline
\end{tabular}

\subsection{BusinesS CYCLE FOR SuPPly ChAIN MANAGEMENT}

Electronic commerce is critical today to enable any type of business, or commercial transaction, and always involves information exchange between stakeholders. Figure 4 shows the Plan-Source-Make-Deliver-Return cycle for managing the manufacturing supply chain. Standards for interactions among manufacturers, suppliers, customers, partners, and even competitors include general business modeling standards (shown in Table 11), and manufacturing specific modeling standards and corresponding message protocols. These standards are the key to enhancing supply chain efficiency and manufacturing agility. Here, we highlight three sets of manufacturing-specific standards critical for integration: APICS Supply Chain Operations Reference (SCOR), Open Applications Group Integration Specification (OAGIS), and MESA's B2MML. 


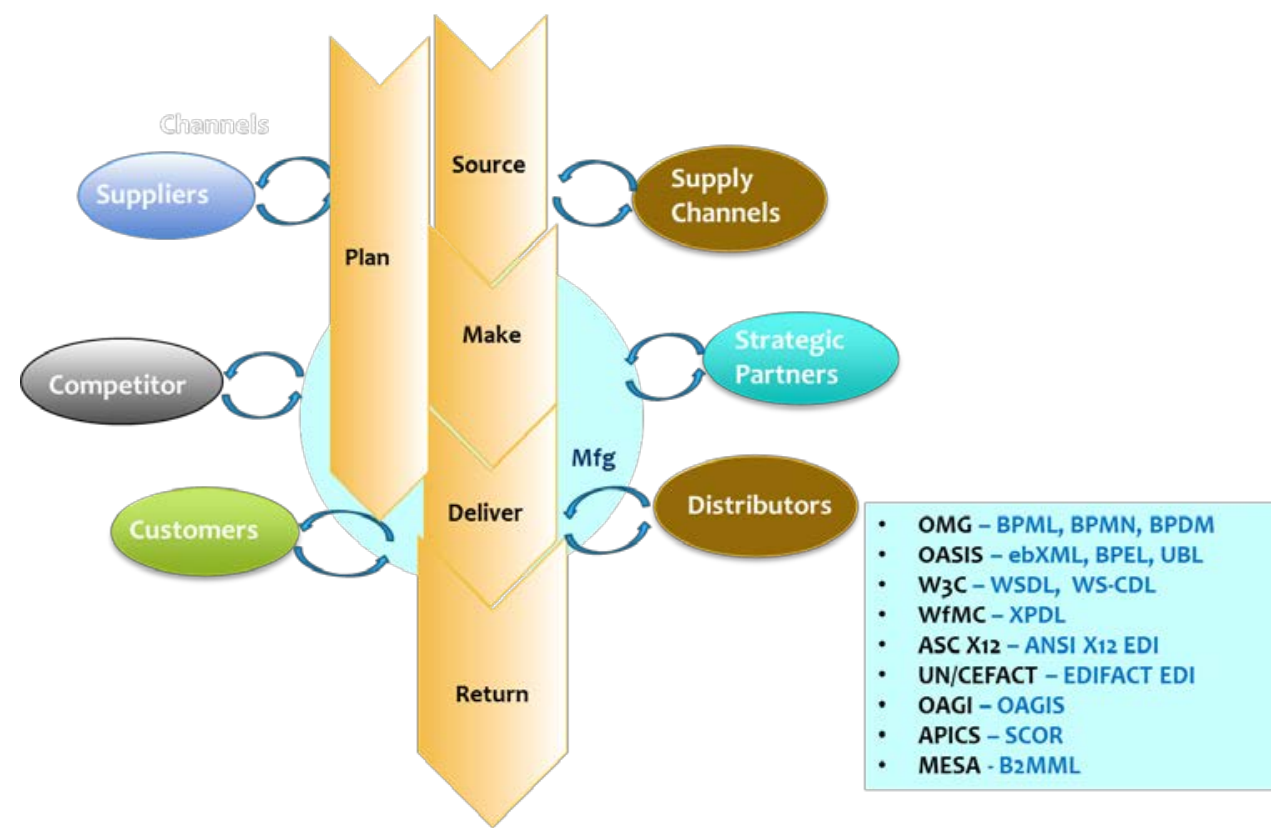

Figure 4: Standards through the supply chain cycle

\section{Table 11: General standards employed for modeling and executing business processes}

\begin{tabular}{|c|c|c|}
\hline SDO & Standards & Description \\
\hline \multirow[t]{2}{*}{ OMG } & BPMN & $\begin{array}{l}\text { Business Process Modeling Notation- A standardized graphical notation for drawing business processes } \\
\text { which also defines a metamodel and interchange format }\end{array}$ \\
\hline & BPDM & Business Process Definition Metamodel - Provides abstract concepts to express business process models \\
\hline WfMC & XPDL & $\begin{array}{l}\text { XML Process Definition Language - business process models that addresses both the graphics and the } \\
\text { semantics and can be executed, stored, and exchanged }\end{array}$ \\
\hline \multirow{3}{*}{ OASIS } & ebXML & $\begin{array}{l}\text { Electronic Business XML - uses the Extensible Markup Language (XML) to standardize the secure } \\
\text { exchange of business data }\end{array}$ \\
\hline & BPEL & $\begin{array}{l}\text { An orchestration language for specifying business process behavior based on Web Services; XML-based } \\
\text { business process models that can be executed, stored, and exchanged }\end{array}$ \\
\hline & UBL & $\begin{array}{l}\text { A generic XML interchange format for business documents that can be customized to meet the } \\
\text { requirements of particular industries }\end{array}$ \\
\hline \multirow{2}{*}{ W3C } & WSDL & $\begin{array}{l}\text { WSDL is an XML format for describing network services as a set of endpoints operating on messages } \\
\text { containing either document-oriented or procedure-oriented information. }\end{array}$ \\
\hline & WS-CDL & $\begin{array}{l}\text { Web Services Choreography Description Language - describes interoperable, peer-to-peer collaborations } \\
\text { between participants }\end{array}$ \\
\hline ASC X12 & ANSI X12 & $\begin{array}{l}\text { One of the most widely adopted Electronic Data Interchange (EDI) document standards developed by } \\
\text { ANSI chartered the Accredited Standards Committee (ASC) X12 }\end{array}$ \\
\hline $\begin{array}{l}\text { UN/ } \\
\text { CEFACT }\end{array}$ & EDIFACT & $\begin{array}{l}\text { Electronic Data Interchange for Administration, Commerce and Transport - an international EDI standard } \\
\text { developed by the United Nations. }\end{array}$ \\
\hline OAGi & OAGIS & $\begin{array}{l}\text { XML based specifications for defining business messages, and for identifying business processes } \\
\text { (scenarios) that allow businesses and business applications to communicate }\end{array}$ \\
\hline APICS & SCOR & $\begin{array}{l}\text { A supply chain framework, linking business processes, performance metrics, practices and people skills } \\
\text { into a unified structure }\end{array}$ \\
\hline MESA & B2MML & An XML implementation of the ANSI/ISA-95, Enterprise-Control System Integration \\
\hline
\end{tabular}


SCOR is a process reference model from the Supply Chain Council (SCC) (now part of APICS) and is a de facto standard that identifies and promotes best practices in the management and operation of supply chain activities across many industries [13]. SCOR is a management tool spanning the supply chain from the supplier's suppliers to the customer's customers. The model describes the business activities associated with all phases of satisfying a customer's demands. The model uses an approach based on three pillars: process modeling and reengineering, performance measurements, and best practices. The SCOR model is text-based and, therefore, not directly usable for automation.

OAGIS includes a suite of engineering and business message specifications called Business Object Documents (BODs), which define common content models and messages for communication between business applications. OAGIS also defines guides for implementation. OAGIS content spans many industries and functions, including electronic commerce, manufacturing, logistics, Customer Relationship Management, and Enterprise Resource Planning (ERP.) It includes not only specific formats for common types of messages used in manufacturing domains, but also mechanisms for extending and tailoring the standards for specific needs. The standard can serve as building blocks for customized data exchanges. MESA B2MML is a well-adopted implementation of the ISA 95 data models. It facilitates the integration of ERP and supply chain management systems with manufacturing systems such as control systems and MES.

\subsection{Manufacturing PyRAmid}

The Manufacturing Pyramid is the core of the SM Ecosystem and is where the product lifecycle, production lifecycle, and business cycle converge and interact. In a smart operation, autonomous and intelligent machine behaviors-including self-awareness, reasoning and planning, and self-correction-are key, but information resulting from these behaviors must flow up and down the Pyramid. This integration from machine to plant to enterprise systems is vital and critically depends upon standards. Standards-enabled SM integration allows 1) access to field and plant data for making quick decisions and optimizing production throughput and quality, 2) accurate measures of energy and material use, and 3) improved shop floor safety and enhanced manufacturing sustainability.

In Figure 5, we divide integration standards based on the ISA 95[34] hierarchy, which has also been included within ISO/IEC 62264 [30]. ISA 95 is a commonly used reference model for developing automated interfaces between enterprise and control systems. This standard was developed for global manufacturers and designed for applicability to all industries and for batch, discrete, and continuous processes alike. 


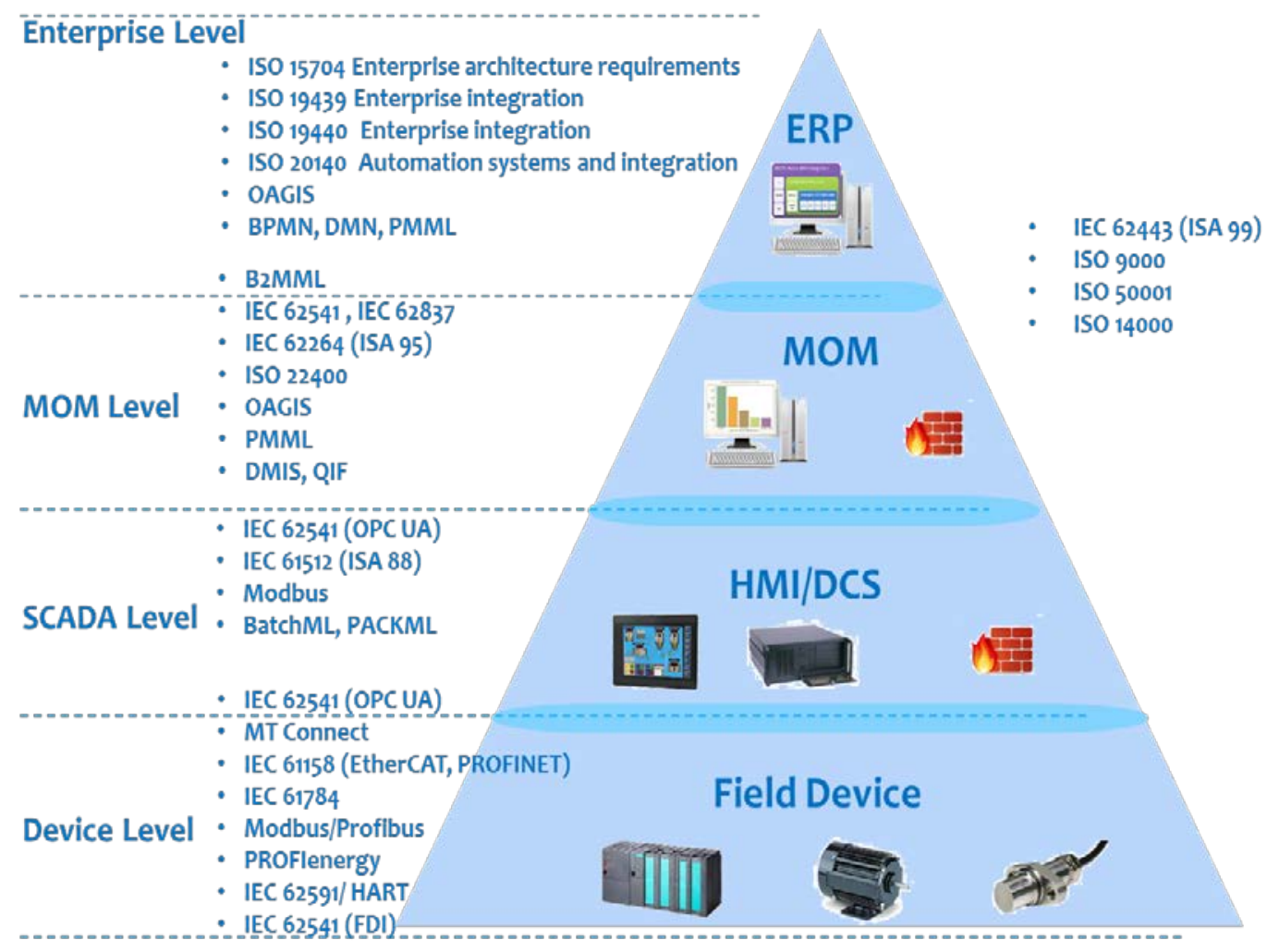

Figure 5: Standards aligned to the ISA95 model

Table 12: Enterprise level standards

\begin{tabular}{|l|l|}
\hline Standards & Description \\
\hline ISO 15704 & $\begin{array}{l}\text { Industrial automation systems -- Requirements for enterprise-reference architectures and methodologies } \\
\text { ISO 19439 }\end{array}$ \\
\hline $\begin{array}{l}\text { Enterprise integration-Framework for enterprise modelling, provides a unified conceptual basis for } \\
\text { model-based enterprise engineering that enables consistency, convergence and interoperability of the } \\
\text { various modelling methodologies and supporting tools. }\end{array}$ \\
\hline ISO 19440 & $\begin{array}{l}\text { Enterprise integration -- Constructs for enterprise modelling, specifies the characteristics of the core } \\
\text { constructs necessary for computer-supported modelling of enterprises conforming to ISO 19439. }\end{array}$ \\
\hline ISO 20140 & $\begin{array}{l}\text { Automation systems and integration -- Evaluating energy efficiency and other factors of manufacturing } \\
\text { systems that influence the environment }\end{array}$ \\
\hline OAGIS & $\begin{array}{l}\text { Open Applications Group Integration Specification (OAGIS) defines a common content model and } \\
\text { common messages for communication between business applications including application-to-application } \\
\text { (A2A) and business-to-business (B2B) integration. }\end{array}$ \\
\hline DMN & $\begin{array}{l}\text { Decision Modeling Notation (DMN) from OMG provides the constructs that are needed to model decisions } \\
\text { to close the gap between the business decision design and decision implementation. DMN notation is } \\
\text { designed to be useable alongside the standard BPMN business process notation. }\end{array}$ \\
\hline PMML & $\begin{array}{l}\text { The Predictive Model Markup Language (PMML) is an XML-based file format developed by the Data } \\
\text { Mining Group to provide a way for applications to describe and exchange models produced by data mining } \\
\text { and machine learning algorithms. It supports common models such as logistic regression and feedforward } \\
\text { neural networks. }\end{array}$ \\
\hline
\end{tabular}


Enterprise level: Table 12 shows important enterprise-level manufacturing standards. ISO 15704 defines requirements for enterprise reference architectures and methodologies. The ISO standards 19439 and 19440 listed in Figure 5 define the framework and specify characteristics of the core constructs needed for enterpriselevel activities. ISO 20140 establishes an overview and general principles of a method for assessment of environmental influence of manufacturing systems. OMG's Business Process Model Notation (BPMN) is a graphical representation often used for specifying processes in a manufacturing business process model. The Predictive Model Markup Language (PMML) developed by the Data Mining Group (DMG) [93] is a format to define statistical and data mining models. PMML can be adopted at the MOM level as well. The Decision Model and Notation (DMN) standard is being developed by OMG to close the gap between business decision design and decision implementation. OAGIS defines a common content model for enterprise application integration.

MOM level: Manufacturing operations management, or MOM, refers to applications that control plant level operations. Table 13 shows some important MOM level standards. IEC 62264 is an international standard for enterprise control system integration and is based upon ISA 95. IEC 62264 defines activity models, function models, and object models in the MOM domain. Business to Manufacturing Markup Language (B2MML), published by the MESA, is an implementation of IEC 62264 to link ERP and Supply Chain Management (SCM) systems with manufacturing systems such as Manufacturing Execution Systems (MES). ISO 22400 defines key performance indicators (KPIs) used in manufacturing operations management. QIF is a suite of standards enabling the flow of information within computer-aided quality measurement systems. PMML from DMG could be applied at this level to support MOM functions.

Table 13: MOM level standards

\begin{tabular}{|l|l|}
\hline Standards & Description \\
\hline IEC 62264 & $\begin{array}{l}\text { Enterprise-control system integration - defines manufacturing hierarchical model, and describes the } \\
\text { manufacturing operations management domain and its activities, the interface content and associated } \\
\text { transactions within Level } 3 \text { and between Level } 3 \text { and Level } 4 \text { and Level } 3 \text { objects. This standard is based } \\
\text { upon ANSI/ISA-95. }\end{array}$ \\
\hline IEC 62541 & $\begin{array}{l}\text { OPC Unified Architecture - an industrial M2M communication protocol for interoperability developed by } \\
\text { the OPC Foundation. }\end{array}$ \\
\hline IEC TR 62837 & $\begin{array}{l}\text { The report on Energy efficiency through automation systems provides a framework for the development } \\
\text { and adaptation of documents in order to improve energy efficiency in manufacturing, process control and } \\
\text { industrial facility management. }\end{array}$ \\
\hline ISO 22400 & $\begin{array}{l}\text { Automation systems and integration -- Key performance indicators (KPIs) for manufacturing operations } \\
\text { management, specifies an industry-neutral framework for defining, composing, exchanging, and using key } \\
\text { performance indicators (KPIs) for manufacturing operations management (MOM), as defined in IEC } \\
\text { 62264-1 for batch, continuous and discrete industries. }\end{array}$ \\
\hline DMIS & $\begin{array}{l}\text { Dimensional Measuring Interface Standard (DMIS) is to provide a standard for the bi-directional } \\
\text { communication of inspection data between computer systems and inspection equipment. }\end{array}$ \\
\hline QIF & $\begin{array}{l}\text { QIF is a unified XML framework standard for computer-aided quality measurement systems. } \\
\text { It enables the capture, use, and re-use of metrology-related information throughout the PLM/PDM domain }\end{array}$ \\
\hline
\end{tabular}

SCADA and Device level: SCADA-level (Supervisory Control And Data Acquisition) and device-level standards in Figure 5 are considered shop floor standards. While these levels were once more distinct, the distinction of interest now is between time and safety critical activities and non-time-critical activities. At shop floor level, there is usually an organized hierarchy of control systems consisting of $\mathrm{HMI}, \mathrm{PLC}$, and field components such as sensors and actuators. PLCs are usually connected to HMI via a non-time-critical communications system such as 
Ethernet/IP, DeviceNet, ControlNet, PROFINET, and EtherCAT. A fieldbus, such as PROFIBUS, CAN bus, HART and Modbus, links the PLCs to the field components. A serial communications protocol, Modbus is also often used to connect a supervisory computer with a remote terminal unit (RTU) in SCADA) systems. While communication profiles of real-time Ethernet-based protocols like EtherCAT, PROFINET and Ethernet/IP are captured by IEC 61874, fieldbuses such as Foundation Fieldbus and PROFIBUS are specified in IEC 61158.

In addition to the communication protocols discussed above, there are several important integration standards linking shop floor control to MES and enterprise level systems, such as OPC and OPC UA (Unified Architecture), MTConnect, PackML and BatchML. OPC UA is an industrial machine-to-machine communication protocol based on Service-Oriented Architecture (SOA). Furthermore, OPC UA provides a flexible information model framework for creating and exposing customized information in a standard way, in those cases where users of OPC UA have agreed on the customizations. Some of these customizations are contained in companion standards for different application areas-for example OPC UA for ISA 95, OPC UA for Field Device Integration (FDI), OPC UA for Analyzer Devices (ADI), and OPC UA for PLCOpen (IEC 61131-3). MTConnect is used to access real-time data from shop floor manufacturing equipment such as machine tools. ISA 88 is a standard for the batch processing industry, and defines the physical model, procedures, and recipes. It was adopted by the IEC in IEC 61512. PackML is a packaging standard used in the batch processing industry as part of ISA 88 standards. BatchML is an implementation of ISA 88 for linking batch control systems to MES. The standards supporting shop floor level manufacturing systems are shown in Table 14.

Table 14: SCADA and device level standards

\begin{tabular}{|c|c|}
\hline Standards & Description \\
\hline IEC 61512 & $\begin{array}{l}\text { ISA- } 88 \text { - defines terminology, reference models, data models (including recipe model) for batch control as } \\
\text { used in the process industries. }\end{array}$ \\
\hline BatchML & BatchML is an XML implementation of the ISA- 88 \\
\hline PackML & $\begin{array}{l}\text { Packaging Machine Language, defines a common approach, or machine language, for automated machines. } \\
\text { PackML was adopted as part of the ISA88 industry standard in August } 2008 .\end{array}$ \\
\hline IEC 62541 & $\begin{array}{l}\text { OPC Unified Architecture - an industrial M2M communication protocol for interoperability developed by } \\
\text { the OPC Foundation. }\end{array}$ \\
\hline IEC 61158 & $\begin{array}{l}\text { The standard specifies industrial communication networks - Fieldbus including ControlNet and } \\
\text { Profibus. }\end{array}$ \\
\hline IEC 61784 & $\begin{array}{l}\text { This standard defines a set of protocol specific communication profiles based on the IEC } 61158 \text { series and } \\
\text { real-time ethernet communication profiles. to be used in the design of devices involved in communications } \\
\text { in factory manufacturing and process control. }\end{array}$ \\
\hline ISO 11898 & $\begin{array}{l}\text { Controller Area network (CAN) -a serial communication protocol that supports distributed real-time control } \\
\text { and multiplexing for use within road vehicles }\end{array}$ \\
\hline IEC 62591 & The standard specifies Wireless communication network and communication profiles - WirelessHART. \\
\hline MTConnect & $\begin{array}{l}\text { MTConnect is a lightweight, open, and extensible protocol designed for the exchange of data from shop } \\
\text { floor equipment to software applications used for monitoring and data analysis. }\end{array}$ \\
\hline $\begin{array}{l}\text { IEC/PAS } 62030 \\
\text { (Modbus) }\end{array}$ & $\begin{array}{l}\text { Modbus is a de facto standard providing serial communications protocol to connect industrial electronic } \\
\text { devices; Modbus is often used to connect a supervisory computer with a remote terminal unit (RTU)/PLC } \\
\text { in supervisory control and data acquisition (SCADA) systems. }\end{array}$ \\
\hline MQTT & $\begin{array}{l}\text { An extremely lightweight publish/subscribe messaging transport for connections with remote locations } \\
\text { where a small code footprint is required and/or network bandwidth is at a premium. }\end{array}$ \\
\hline
\end{tabular}


Cross-levels: As shown on the right side of Figure 5, several standards cross all the levels and define manufacturing system security, quality management processes, energy management, and environmental management. Table 15 lists several cross-level manufacturing standards. ISA/IEC-62443, formerly ISA 99, is a series of standards, technical reports, and related information that defines procedures for implementing electronically secure industrial automation and control systems. The concept of manufacturing and control systems electronic security is applied in the broadest possible sense, encompassing all types of plants, facilities, and systems in all industries. The ISO 9000 family of quality management systems standards is designed to help manufacturers ensure that they meet the needs of customers and other stakeholders while meeting statutory and regulatory requirements related to a product. ISO 50001 specifies the requirements for establishing, implementing, maintaining and improving energy management systems for a manufacturing business. ISO 14000 is a series of environmental management standards containing guidance on how to systematize and improve environmental management efforts.

Table 15: Cross-level standards

\begin{tabular}{|l|l|}
\hline Standards & Description \\
\hline $\begin{array}{l}\text { IEC 62443 } \\
\text { (ISA 99) }\end{array}$ & $\begin{array}{l}\text { IEC-62443 defines procedures for implementing electronically secure Industrial Automation and Control } \\
\text { Systems (IACS). }\end{array}$ \\
\hline ISO 9000 & $\begin{array}{l}\text { ISO } 9000 \text { is a quality management standard that presents guidelines intended to increase business } \\
\text { efficiency and customer satisfaction. }\end{array}$ \\
\hline ISO 50001 & $\begin{array}{l}\text { The standard specifies the requirements for establishing, implementing, maintaining and improving an } \\
\text { energy management system, to improve organizations energy performance, including energy efficiency, } \\
\text { energy security, energy use and consumption }\end{array}$ \\
\hline ISO 14000 & $\begin{array}{l}\text { The ISO 14000 family of standards provides practical tools for companies and organizations of all kinds } \\
\text { looking to manage their environmental responsibilities. }\end{array}$ \\
\hline
\end{tabular}

\subsection{StANDARDS AdOPTION AND THE RELATED ISSUES}

Standards play a big role in economic growth globally. Roughly, $80 \%$ of global merchandise trade is affected by standards and by regulations that embody standards [84]. In the United States, the economic impact of standards is not tracked [85]. Based on a UK study published in 2005, the Empirical Economics of Standards, standards make an annual contribution of 2.5 billion to the UK economy and $13 \%$ of the growth in labor productivity is attributed to the role of standards [86]. A study of the economic benefits of standardization undertaken by the German Institute for Standardization (DIN) and the German Federal Ministry of Economic Affairs and Technology from 1997-2000 based on 700 companies found the benefit of standards to the national economy is greater than $\$ 15$ billion per year [87]. They also found that companies that participate in standards development have a head start on their competitors in adapting market demands and new technologies.

Standards are key enablers for manufacturing. They provide a basis on which to bring together specialized expertise to create highly efficient manufacturing systems. The sum total of standardization efforts in the manufacturing field is immense. Standards provide data definitions, detailed models of the information relationships, and interface protocols for all three of the lifecycles we describe. They support product designs and management, production system design and operations, and integration into business value chains. These 
are the foundations on which information can flow throughout the levels of manufacturing control and between partners in the manufacturing enterprise including the various software vendors and device providers that participate by providing their expertise to these systems in the form of commercial products. Standards allow for a clear separation of concerns among the participants, effectively bringing down costs while increasing reliability and efficiency.

Across some of the lifecycles and in some industry sectors standards are more mature than in others. In discrete manufacturing, which is characterized by individual parts that are assembled into final products, standards along the product lifecycle are fairly well positioned to support Smart Manufacturing. In the world of continuous manufacturing, however, standards are not as well established for process product data management. Production systems engineering standards are more diversified and can typically be applied in both categories of manufacturing. Within the manufacturing pyramid, communication standards are well established but interoperability among systems is somewhat limited, meaning that manufacturers typically are locked into a single vendor solution. Along the business lifecycle, several well-established standards exist however; the level to which information is able to interconnect with the production systems is quite limited. Other gaps in the ability of standards to address smart manufacturing needs exist and are discussed in detail in next section.

Beyond the standards gaps two other barriers to standards adoption inhibit the growth of SMS.

1) Lack of tracking of standards and standards adoption. The huge number of standards can be misleading, as many standards are never used. The number of standards that are actively being sold constitute a small part of those offered for sale, meaning many standards out there are not being used. In 1996, a NIST report identified $25-30 \%$ of the US standards as obsolete [83] and certainly, this number has grown. SDOs rarely inactivate standards once they have been published. The result is that manufacturers and their support network, in the form of software and device providers, are left trying to navigate the standards without a compass to help them find their way.

2) Overlap and redundancy between standards. Three practices cause overlap and redundancy. First standards from national, regional, international standards systems are sometimes identical, equivalent or in some other way related resulting in confusion as to the most authoritative source. Secondly, standards in the same technical areas but in different application sectors are defined independently. For example, material-testing methods defined for different industry sectors sometimes are not consistent. For the US, the third redundancy comes from the pluralistic standards system. In a pluralistic standards system, no one body is sanctioned to provide standards. The system reflects cultural individualization and an in-grained belief in a market-driven economy. In US, there are 600 SDOs maintaining ongoing standardization programs. As the number of standards produced expands, more opportunity for overlap and redundancy results. Standards organizations are not only competing with one another to write standards, they are sometimes writing conflicting standards, thus defeating the purpose. In the words of an old programmer, "Are we creating spaghetti code in our standards?"

To tackle the issues of untracked and overlapping standards, harmonization and collaboration among SDOs are necessary. Harmonized standards as defined by ISO are "equivalent standards on the same subject approved by different standardization bodies that establish interchangeability of products, processes and services, mutual understanding of test results or information provided according to these standards" [94].

Historically, there have been several attempts at standards harmonization. The first international harmonization occurred when ISO was formed in 1947. Before the World War II, standards throughout the world were national in scope, often set by government-funded national standards bodies. Standards were developed to serve a 
country's particular needs and to benefit the domestic supplier. However, standards for similar products approved by different national standards bodies create difficulties for global companies. Trade barriers result in that products designed for one market may be blocked out of other markets based on the different national requirements. ISO was created to facilitate trade by opening up the markets globally [91]. We now see a trend for many SDOs to be global. Many of the organizations we have mentioned have evolved into international organizations from their national origins, often dropping the original meanings of their acronymized names at the same time. In the US government policy shifted away from government specific standards (known as Federal Information Processing Standards or FIPS and United States Military Standards or MILSPECS) to adopting publically developed standards from SDOs. A decade ago, $80 \%$ of all standardization activities of the European standards bodies focused on national work, with the remainder related to international development efforts. Today, this ratio is reversed: $80 \%$ of standards work is international [88]. Where overlap exists between standards organizations, it is typical to have at least a liaison that is responsible for mediating differences. SDOs will often establish joint working groups as well.

To summarize, in this age of smart manufacturing demands for further standards harmonization and a proactive way to develop and implement ubiquitous standards are greater than ever before. For manufacturers to embrace emerging information and communication technology, serve global markets and innovative business models, and provide rapid evolutions of product designs and new technology, strong standards underpinnings that are clear and unambiguous are needed. The standards landscape presented here identifies areas of technical interaction between the different standards efforts.

\section{STANDARDS OPPORTUNITIES FOR SMART MANUFACTURING}

Most standards for manufacturing created in the last 30 years have already achieved a high degree of maturity; however, to enable SMS, further standards development is necessary. We identify several areas in the SM Ecosystem where standards can be extended or where new standards should be developed, and we identify some new initiatives focused on SMS that will spur the development of both SMS technology and standards.

\subsection{StANDARDS NeEDS}

Full realization of SMS capabilities will require replacement of the classical manufacturing system architectural paradigm based on a hierarchical control model [45]. Figure 6 shows a new paradigm based on distributed manufacturing services, also called Cyber Physical Production Systems (CPPS). ${ }^{8}$ The paradigm shift is made possible by the introduction of smart devices accessible as services on a network, more embedded intelligence at every level, predictive analytics that enable responsive control, and cloud technology that enables virtualization of control and engineering functions at all hierarchical levels. With these capabilities in place, widespread automation across hierarchical levels using new approaches to control is a realistic possibility.

\footnotetext{
${ }^{8}$ Smart devices are at the core of the area of technology development that has become known as Cyber Physical Systems, or CPS, of which CPPS is a part.
} 


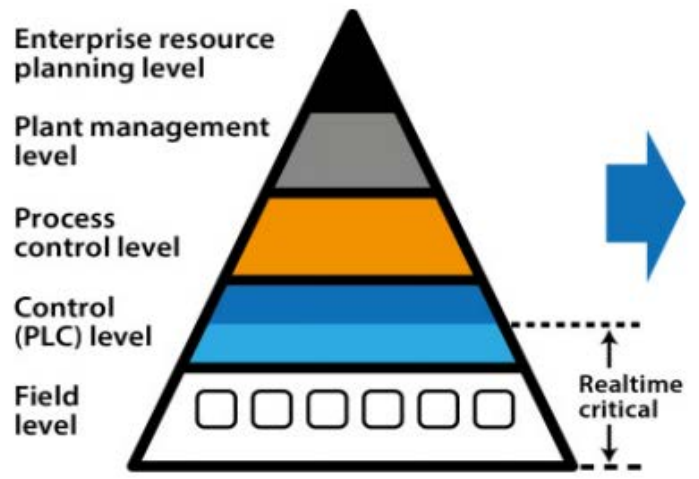

Automation hierarchy

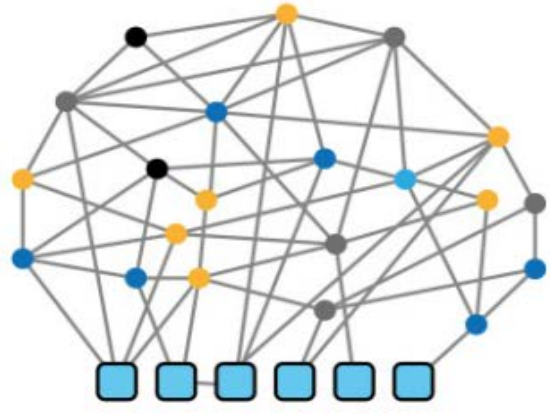

CPS-based Automation

Figure 6: Decomposition of the automation hierarchy with distributed services [55]

The new service-oriented paradigm ultimately transforms the smart manufacturing ecosystem into a fully connected and integrated system, shown in Figure 7. All the manufacturing functions along three dimensions and in the manufacturing pyramid can be virtualized and hosted as services, except those time-critical and safety-critical manufacturing functions remaining at the shop floor level.

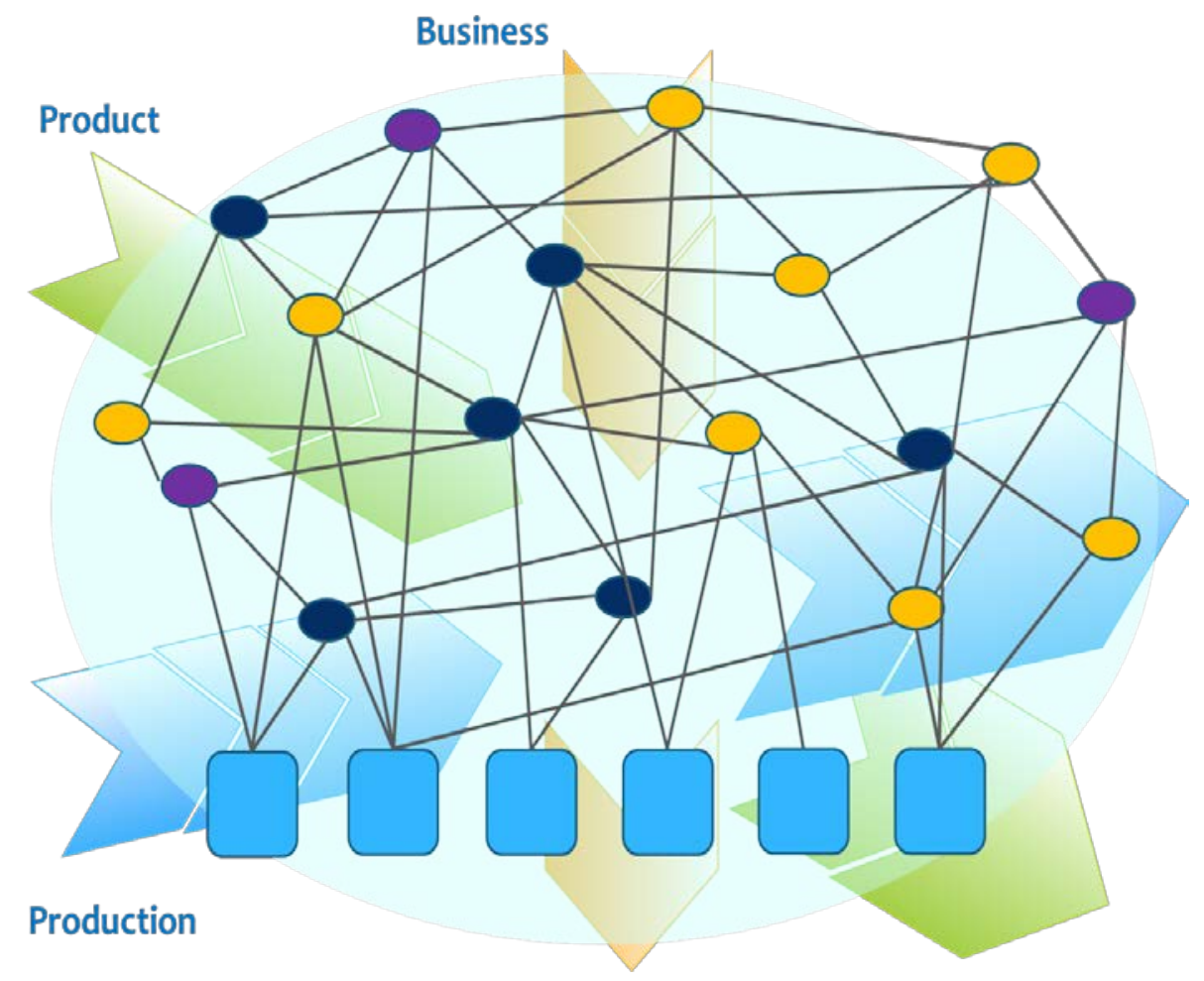

Figure 7: Service-oriented smart manufacturing ecosystem

Existing manufacturing standards are far from being sufficient for the service-oriented smart manufacturing ecosystem. Areas that need new standards support include reference architecture, cybersecurity, factory networking, supply chain integration, and data transfer from factory floor to enterprise level. Table 16 lists these standards' opportunities and the types of capabilities they support. Specifically, new or improved standards in 
these areas would improve capabilities associated with agility $(A)$, quality $(Q)$, productivity $(P)$ and sustainability (S). The first column is the area of opportunity for new standards. The second column shows where the standards impact the SM Ecosystem-Product Lifecycle (PL), Production System Lifecycle (PSL), Business Cycle (BC), and Smart Production Pyramid (SPP). The third column shows how the standards map to SMS capabilities. Note that we present this not as a complete list, but rather as a starting point for exploration and discussion of the infrastructure of SM standards.

Table 16: Opportunities for Standards for SM Capabilities

\begin{tabular}{|c|c|c|c|c|c|c|c|c|}
\hline \multirow{2}{*}{$\begin{array}{l}\text { Standards } \\
\text { Opportunity }\end{array}$} & \multicolumn{4}{|c|}{ Eco System Dimension } & \multicolumn{4}{|c|}{ Capability Supported } \\
\hline & $\begin{array}{l}\text { Product } \\
\text { Lifecycle }\end{array}$ & $\begin{array}{l}\text { Production } \\
\text { Lifecycle }\end{array}$ & $\begin{array}{l}\text { Business } \\
\text { Cycle }\end{array}$ & $\begin{array}{l}\text { Mfg } \\
\text { Pyramid }\end{array}$ & Agility & $\begin{array}{l}\text { Product } \\
\text { ivity }\end{array}$ & Quality & $\begin{array}{l}\text { Sustain- } \\
\text { ability }\end{array}$ \\
\hline Cyber Security & $\mathrm{X}$ & $\mathrm{X}$ & $\mathrm{X}$ & $\mathrm{X}$ & $\mathrm{X}$ & $\mathrm{X}$ & $\mathrm{X}$ & \\
\hline $\begin{array}{l}\text { SMS Reference Model } \\
\text { and Reference } \\
\text { Architecture }\end{array}$ & $\mathrm{X}$ & $\mathrm{X}$ & $\mathrm{X}$ & $\mathrm{X}$ & $\mathrm{X}$ & $\mathrm{X}$ & $\mathrm{X}$ & $\mathrm{X}$ \\
\hline $\begin{array}{l}\text { CPPS Reference } \\
\text { Architecture }\end{array}$ & & $\mathrm{X}$ & & $\mathrm{X}$ & $\mathrm{X}$ & & $\mathrm{X}$ & $\mathrm{X}$ \\
\hline $\begin{array}{l}\text { Smart Device Information } \\
\text { Model }\end{array}$ & & $\mathrm{X}$ & & $\mathrm{X}$ & $\mathrm{X}$ & $\mathrm{X}$ & & \\
\hline $\begin{array}{l}\text { Intelligent Machine } \\
\text { Communication Standards }\end{array}$ & & & & $\mathrm{X}$ & $\mathrm{X}$ & $\mathrm{X}$ & $\mathrm{X}$ & $\mathrm{X}$ \\
\hline Human Machine Interface & & $\mathrm{X}$ & & $\mathrm{X}$ & $\mathrm{X}$ & $\mathrm{X}$ & $\mathrm{X}$ & \\
\hline PLM/MES Integration & $\mathrm{X}$ & $\mathrm{X}$ & & $\mathrm{X}$ & $\mathrm{X}$ & $\mathrm{X}$ & $\mathrm{X}$ & $\mathrm{X}$ \\
\hline Cloud Manufacturing & $\mathrm{X}$ & $\mathrm{X}$ & $\mathrm{X}$ & $\mathrm{X}$ & $\mathrm{X}$ & $\mathrm{X}$ & & \\
\hline $\begin{array}{l}\text { Manufacturing } \\
\text { Sustainability }\end{array}$ & $\mathrm{X}$ & $\mathrm{X}$ & $\mathrm{X}$ & $\mathrm{X}$ & & & & $\mathrm{X}$ \\
\hline
\end{tabular}

As shown in the table, a high-level reference architecture for SMS, including functional models and architectural definitions, is needed to integrate functions within and across the extended enterprise, including between suppliers and customers. These models will form the basis for dynamic production capabilities and customization of end products.

Information models representing smart devices on the shop floor and manufacturing services are also needed to increase productivity and agility by supporting reconfiguration of equipment, as well as allowing more optimal health maintenance. A reference architecture for CPPS will enable development of production modules incorporating smart devices. As these systems of systems come into place, intelligent machine communication standards along with an architectural framework will allow automation of system-level controls and transparency of data from the lowest levels of manufacturing to higher control levels.

This increase of automation possibilities brings a need for new types of interfaces for humans to interact with the machines. Much of the performance data for individual machines can be presented to people through dashboards that also enable direct control. Similarly, dashboards for monitoring and controlling system-wide performance are needed. Optimization of these interfaces is an area of active research, and related standards should accordingly follow. ISA formed an HMI committee to establish standards, recommend practices, and 
provide technical reports relating to human-machine interfaces (HMIs) in manufacturing and processing applications.

In addition, for production system design, operational data from manufacturing is needed to generate new designs and better process plans more quickly. Although it is an area of research, no explicit standards yet exist to assess production system capabilities and to link the results back to upstream activities in the lifecycle.

For product lifecycle management, AMP 2.0 [5] recommends an ontology of data and artifacts that captures, stores, visualizes, searches, and shares both static and dynamic data, both along the product lifecycle and through the supply chain. The development of such a standard will enable more agility in the supply chain and reuse of products designs for rapid redesign.

Product lifecycle data combined with data from manufacturing processes can enable advanced analyses of the processes themselves, resulting in process improvement in terms of productivity, sustainability, and quality. For instance, analysis of product performance in the field can sometimes reveal quality issues in production.

One vision for SMS is that products themselves can contain the history of how, when, and where they were manufactured. The MTConnect Institute is starting standards activities that will enable this type of traceability. Technology and standards for big data and cloud manufacturing will allow many types of advanced analysis and other functions to be provided on a service basis, thereby making them more readily accessible to manufacturers.

Standards related to sustainability evaluation for manufacturing systems are evolving along each of the dimensions described. Current practices for sustainability evaluation for manufacturing follow the Life Cycle Assessment (LCA) methodology standardized in the ISO 14000 series on environmental management. These standards operate from a management perspective and use a top-down approach to estimating sustainability impacts of different processes involved in goods production. In SMS, we envision more accurate measures of the sustainability impacts of each of the manufacturing processes based on measures of operational data for each process. These measures will allow more accurate accounting of the impacts of individual decisions at each production facility. Still, many challenges will exist since sustainability assessment, by its very nature, must address tradeoffs between many criteria. How this data can be used along each of the dimensions of the SMS ecosystem and how sustainability impacts are apportioned to the different aspects of production and the product are grand challenges for sustainability assessment. Standards are necessary to provide unambiguous and comparable data to support this decision-making process.

\subsection{NEW INITIATIVES}

Most of the standards areas that we described are being extended to address SMS capabilities. Quite a few new initiatives worldwide have emerged to contribute to the standards and opportunities identified above.

\subsubsection{Industrie 4.0}

Industrie 4.0 is a key initiative in Germany containing a technical strategy for achieving SMS. The enablers of Industrie 4.0 are the internet, mobile computing, and cloud computing technologies. A goal of Industrie 4.0 is the creation of innovations including smart products, smart production systems, smart factories, and smart logistics running in a decentralized and dynamic fashion [56]. The Industry 4.0 working group recommended standardization and open standards for a reference architecture as the first priority for implementation [57]. Following this recommendation, the German Commission for Electrical, Electronic \& Information Technologies (DKE) produced a standardization roadmap in 2014 [17]. In parallel, Platform Industrie 4.0 projects were established by a number of German associations to form interdisciplinary working groups on issues for future 
standardization. The result is the Reference Architectural Model (RAMI) 4.0 and the Industrie 4.0 components [58] that describe functional models for CPPS. These will serve industry as a basis for developing future products and business models in Germany.

\subsubsection{Internet of Things (loT)}

In the area of the Internet of Things (IOT), the Europe Union (EU) founded several projects to develop an loT reference model and reference architecture. IoT-A, an EU Seventh Framework Project, created an architectural reference model envisioned as a foundation for the Internet of Things [62]. loT@Work is another EU project led by Siemens AG that focuses on harnessing loT technologies in industrial and automation environments [63]. Three main scenarios providing requirements for the loT@Work architecture include agile manufacturing, largescale manufacturing, and remote maintenance.

In the U.S., the Industrial Internet Consortium (IIC) [36] founded by GE, IBM, CISCO, Intel, and AT\&T is a transatlantic cousin of Industrie 4.0. IIC is concerned with anything that can be connected to the internet, provide data as feedback, and raise efficiency. Its scope is larger than Industrie 4.0 in that it addresses not only manufacturing systems, but also energy, healthcare, and infrastructure. Unlike Industrie 4.0, which works on standards directly, IIC has set a goal to "define and develop the reference architecture and frameworks necessary for interoperability" and which might help set future standards. Table 17 shows a comparison between Industrie 4.0 and IIC from [60].

Table 17: Comparison of Industrie 4.0 and the Industrial Internet Consortium [60]

\begin{tabular}{|c|c|c|}
\hline & Industry 4.0 & The Industrial Internet Consortium \\
\hline Key authors & German government & Large multinationals \\
\hline Key stakeholders & Government, academia, business & Business, academia, government \\
\hline Taxonomy of revolutions & Four revolutions & Three revolutions \\
\hline Support platforms & German industrial policy & Open membership non profit consortium \\
\hline Sectoral focus & Industry & $\begin{array}{l}\text { Manufacturing, energy, transportation, } \\
\text { healthcare, utilities, cities, agriculture }\end{array}$ \\
\hline Technological focus & $\begin{array}{l}\text { Supply chain coordination, embedded } \\
\text { systems, automation, robots }\end{array}$ & $\begin{array}{l}\text { Device communication, data flows, device } \\
\text { controls and integration, predictive analytics, } \\
\text { industrial automation }\end{array}$ \\
\hline Holistic focus & Hardware & Software, hardware, integration \\
\hline Geographical focus & Germany and its company & Global marketplace \\
\hline Corporate focus & SMEs & Companies of all sizes \\
\hline Optimization focus & Production optimization & Asset optimization \\
\hline Standardization focus & On agenda & Recommendations to standards organizations \\
\hline Economic approach & Normative economics & Positive economics \\
\hline Overall Business approach & Reactive & Proactive \\
\hline
\end{tabular}

Meanwhile, the Open Interconnect Consortium (OIC), founded by leading technology companies like Samsung, Cisco, GE, and Intel, is proposing an open-source solution to enable device-to-device connectivity for loT [61]. OIC focuses on building a common communications standard and sponsors the loTivity project to build an opensource reference implementation of those specifications. The adoption of the OIC standard is expected to begin in consumer electronics and expand over time to industrial applications. 
Open Machine communication standards are one of the key enablers of IoT implementation. The diversified IoT use scenarios mean that there will be no single 'winner' in terms of Machine-to-Machine (M2M) standards. Initiatives such as OneM2M [66], HyperCat [68], OMA LightweightM2M [67], Eclipse M2M [68] and Weightless [70] have potential to be de facto M2M standards [65]. Specifically, Eclipse SCADA will provide connectivity to a variety of industrial devices and offer a monitoring system to create alarms and events and record historical data and a framework to build custom user interfaces and visualizations for those functions [71]. A new ETSI (European Telecommunications Standards Institute) Technical Committee is also developing standards for M2M Communications in cellular segment for loT applications in industrial automation, heath care, and supply chains [64].

\subsubsection{Cyber Physical Systems (CPS)}

While the loT deals with unique, identifiable, and internet-connected physical objects, cyber-physical systems efforts are concerned with the nature of cyber-physical coupling and the system of systems characteristics of software-controlled systems. Standards for CPS include a reference architecture, common services and functional models, semantics, security and safety standards, and standard interfaces for system-to-system interactions. A public working group led by NIST is working on terminology and a reference architecture for CPS [72]. CPS research and standards development are being worked on in multiple NIST Laboratories in programs on advanced manufacturing, cybersecurity, buildings and structures, disaster resilience, and smart grid. NIST efforts include work on Industrial Control Systems (ICS) as well. In Europe, the EU has invested significantly in CPS through its ARTEMIS and ECSEL JU programs and Smart CPS projects under the Horizon 2020 plan [73]. The Association for German Engineers founded Technical Committee 7:20 - Cyber-Physical Systems to support standards development in CPS from the perspective of automation technology [74].

\subsubsection{Big Data and Cloud Manufacturing}

The amount of data in manufacturing systems is exploding. Big-data analytics enables continuous innovation and process improvement of manufacturing systems, and has been recognized as a key enabler of SMS [80]. With a cloud-computing infrastructure, manufacturers gain the ability to access software and real-time data at lower cost and to respond quicker to customer issues. The IEEE Standards Association has introduced a number of standards related to big-data and cloud applications, including IEEE 2200-2012, IEEE 6136, and IEEE P2302. ISO/IEC JTC 1 recognized data analytics as an important future area for focus and established a Study Group on Big Data to identify standards gaps and propose standardization priorities to serve as a basis for future JTC 1 work [76]. NIST established a public working group to propose a reference architecture and identify standards related to Big Data, a fundamental technology for SMS [42]. While technology development in this area will have a huge impact on manufacturing, none of these activities are specifically directed at manufacturing. In May 2015, NIST and OAGI jointly held a Workshop on Open Cloud Architectures for Smart Manufacturing [78].

\subsubsection{Smart Manufacturing Initiatives in the U.S.}

While most of the existing consortia and professional societies in the U.S. are addressing SMS in some ways, several industrial consortia formed to address broader, overarching, needs of SMS. The oldest of these is the Smart Manufacturing Leadership Coalition (SMLC), a non-profit organization committed to the creation of a scaled, shared, infrastructure called the Smart Manufacturing Platform [75]. SMLC activities will help set future standards in integrating SM applications. Subsequently, the U.S. government initiated a series of institutes to support U.S. manufacturing. These institutes collectively called the National Network of Manufacturing Institutes, or NNMI, address different challenge areas for advanced manufacturing. The Digital Manufacturing and Design Innovation Institute (DMDII) most closely aligns with the SMS needs for information flow throughout 
an enterprise to enable the SMS capabilities-agility, quality, productivity, and sustainability. DMDII has issued three rounds of project calls in areas of strategic importance, including intelligent machine communication standards and cyber-physical manufacturing operating systems. In 2014, the U.S. Department of Energy announced intention to create another institute for clean-energy manufacturing based on smart manufacturing technology, including advanced sensors, controls, platforms, and modeling technology for energy efficiency.

The National Institute of Standards and Technology (NIST) has several initiatives addressing Smart Manufacturing. NIST is heavily engaged in efforts to develop new standards for the Digital Thread [39], ModelBased Enterprise [40], smart manufacturing design and analysis [95], additive manufacturing [97] and robotics [96]. NIST leads an effort to define requirements eventually leading to standards for cloud-based services for manufacturing. NIST work on cyber security for supply chains and industrial systems will have great importance for manufacturers [43]. Finally, NIST coordinates the networking of the NNMIs within the U.S. [44].

\subsubsection{SDO Smart Manufacturing Related Activities}

Various SDO activities are starting to focus explicitly on the needs for and impacts of the technologies fundamental to SMS-IoT, cloud computing, Big Data, and analytics. To help ensure the existence of adequate standards support for SM, in 2014 the IEC Standardization Management Board (SMB) set up a new Strategic Group, SG 8: Industry 4.0 - Smart Manufacturing. Its scope includes defining terminology, summarizing existing standards and standardization projects in progress, and developing a common strategy for implementation of smart manufacturing [59]. SG 8 will also foster relationships between IEC (TC3, TC 65) and institutions like ISO (TC 184), ISA, and IEEE on SM standards development. In 2015, the ISO Technical Management Board (TMB) passed a resolution to form an ISO/TMB Strategic Advisory Group on Industry 4.0/Smart Manufacturing. The SAG is tasked to provide a definition of, and give an overview on, available standards, use cases, and current work related to Industry 4.0/Smart manufacturing; to identify possible gaps where additional standards are needed; and to make recommendations on actions to be taken by TMB [82]. In the Fall of 2014, MESA launched the Smart Manufacturing Working Group to better orchestrate their projects related to Smart Manufacturing. Outputs from this group will include things such as expansion of MESA's 'Collaborative Manufacturing Dictionary' and a library of 'Manufacturing Business Processes' and 'Use Cases' that map production processes across internal operating departments and supply chains [74]. OAGI also established a Smart Manufacturing working group to develop multi-tiered supply chain collaboration guidelines and standards for engineered components to improve cost, quality, agility and more. Similarly, ASTM has established a Smart Manufacturing Advisory Board to guide their efforts.

\subsubsection{Sustainable Manufacturing Standards}

Typically, sustainability is discussed from three perspectives: environment, economic, and social. The focus of our study is on data and information that can be collected by a manufacturing organization rather than on organizational policies and practices. In 2008, ASTM formed a committee on Sustainability and subsequently formed a subcommittee specifically addressing Sustainable Manufacturing. While the standards of this subcommittee are not yet complete, we expect an initial set on the near-term horizon for enabling analysis of how manufacturing systems are impacting sustainability and can be improve in this respect. A focus of the ASTM standards is on characterizing manufacturing processes for environmental sustainability assessment. Sustainability is inherently a complex area in which multiple tradeoffs must be considered. In order to evaluate those trade-offs, accurate data reflecting the impact of individual activities and processing leading to the creation of some good or service is necessary. Until now, such data was very difficult and costly to obtain. Direct measure of the use of physical resources is now quantifiable and thus the focus of the standardization activities. 
In addition, ISO 22400 has initiated an addendum standard on KPIs for energy management specifically. A wide range of other activities focuses on assessing social factors related to sustainability. These include organizational practices and policies and do not fall within the scope of this study. Economic aspects of sustainability are also not specifically addressed, but the data gathered for SMS will be ultimately useful in these assessments as well. For instance, when trying to understand issues of resource efficiency, one must take an economic viewpoint and factor that against measures of resource utilization.

\section{CONCLUSION}

In order to realize the vision of smart manufacturing, the classical manufacturing system architectural paradigm based on a hierarchical control model must be replaced. A new paradigm based on distributed manufacturing services is evolving. This paradigm shift is brought on by the introduction of smart devices accessible as services on a network, embedded intelligence at every level, predictive analytics, and cloud computing technology. All of these technologies depend on standards.

Standards are a fundamental component of the evolution to smart manufacturing. Standards allow for systematic, repeatable, and efficient manufacturing systems. Standards support the participation of a wide range of organizations from small manufacturers to large multi-national corporations. Moreover, smart manufacturing technologies enabled by standards allow for participation of a wide range of manufacturers, regardless of size or location.

This report presents an examination of the standards landscape for smart manufacturing. The landscape comprises standards used to integrate within and across three manufacturing lifecycle dimensions - the product lifecycle, the production system lifecycle, and the business (enterprise) lifecycle. In order to study existing standards and how they can be applied to smart manufacturing, we have defined a Smart Manufacturing Ecosystem to provide a consistent context for analyzing existing standards and establishing future standards requirements for smart manufacturing. In this report, the SMS Ecosystem is used as a basis to categorize and evaluate existing standards for application to smart manufacturing systems, present a comprehensive view of emerging SMS standardization activities, and identify areas where new standards activities are needed to enable the implementation of SMS.

The report concludes that existing manufacturing standards are insufficient to fully enable smart manufacturing, especially in the areas of cybersecurity, cloud-based manufacturing services, supply chain integration, and data analytics. Traditional standards development efforts, primarily focused on incremental improvements of existing standards, cannot keep pace with the speed of evolving technology. SDOs, national manufacturing initiatives, and industrial consortia are identifying requirements for new smart manufacturing standards.

The report identified the following as priority areas for standards advancement to enable smart manufacturing:

- SMS reference model and reference architecture

- Internet of Things (IOT) reference architecture for manufacturing

- Manufacturing service models

- Machine to machine communication

- PLM/MES/ERP/SCM/CRM integration 
- Cloud manufacturing

- Manufacturing sustainability

- Manufacturing cybersecurity

Finally, the report examined sources of new requirements for standards to support smart manufacturing, including national and international manufacturing initiatives, the Internet of Things initiative, standards development organization manufacturing programs, and the emergence of sustainable manufacturing requirements.

\section{REFERENCES}

[1] Global Agenda Council on the Future of Manufacturing, The Future of Manufacturing: Driving Capabilities, Enabling Investments, URL:

http://www.cggc.duke.edu/pdfs/Future_of_Manufacturing_Driving_Capabilities.pdf, Access date March 14, 2015

[2] S. S. Shipp, N. Gupta, B. Lal, J. A. Scott, C. L. Weber, M. S. Finnin, M. Blake, S. Newsome, and S. Thomas, 2012, Emerging global trends in advanced manufacturing, Institute for Defense Analyses, Virginia, US.

[3] J. Davis' T. Edgar, J. Porter, J. Bernaden, M. Sarli, Smart Manufacturing, manufacturing intelligence and demand-dynamics performance. Computers \& Chemical Engineering, 2012, 47,145-156.

[4] SMLC, Implementing $21^{\text {st }}$ Century Smart Manufacturing: Workshop Summary Report, June 2011, http://www.energetics.com /resourcecenter/products/roadmaps/Documents/SMLC_Smart_Manufacturing.pdf, Access date March 8, 2015.

[5] PCAST AMP Steering Committee Report - Accelerating U.S. Advanced Manufacturing, October 27, 2014.

[6] NIST Standards.gov, What are Standards? http://www.nist.gov/standardsgov/definestandards.cfm.

[7] Gunasekaran, Agile Manufacturing: The 21st Century Competitive Strategy, Elsevier, 2001

[8] LNS Research, 2013. 28 Manufacturing Metrics that Actually Matter, http://blog.Insresearch.com/blog/bid/188295/28-Manufacturing-Metrics-that-Actually-Matter-TheOnes-We-Rely-On.

[9] International Trade Administration, How does Commerce define Sustainable Manufacturing? 2010, http://www.trade.gov/competitiveness/sustainablemanufacturing/how doc defines SM.asp.

[10]PCAST AMP Steering Committee Report - Accelerating U.S. Advanced Manufacturing, Annex 1-10: Transformative Manufacturing Technology, October 27, 2014.

[11]P. Witherell, B. Kulvatunyou, and S. Rachu, Toward the Synthesis of Product Knowledge across the Lifecycle, Proceedings of the ASME 2013 International Mechanical Engineering Congress \& Exposition IMECE2013, November 13-21, 2013, San Diego, California, USA

[12]S. Faltinski, O. Niggemann, N. Moriz, A. Mankowski, AutomationML: From Data Exchange to System Planning and Simulation, 2012 IEEE International Conference on Industrial Technology (ICIT), Athens, Greek.

[13]P. Bolstorff, R. Rosenbaum (2003). Supply Chain Excellence: A Handbook for Dramatic Improvement Using the SCOR Model. AMACOM Div American Mgmt Assn. ISBN 0-8144-0730-7.

[14]D. Kibira, KC Morris, Background Study of Methods and Tools for Performance Assurance of Smart Manufacturing Systems, forthcoming NISTIR.

[15]CIMOSA, CIM Open System Architecture. URL: http://www.pera.net/Methodologies/Cimosa/CIMOSA.html, Access date March 8, 2015. 
[16]R. Sessions, A Comparison of the Top Four Enterprise-Architecture Methodologies, URL: https://msdn.microsoft.com/en-us /library/bb466232.aspx. Access date March 8, 2015.

[17]German Standardization Roadmap, Industry 4.0. URL:

https://www.dke.de/de/std/documents/rz_roadmap\%20industrie\%204-0_engl_web.pdf, Access date March 14, 2015.

[18]S. Rachuri, KC Morris, U. Roy, D. Dornfeld, S. Kumara, "Sustainable Manufacturing Program Workshop Report," NISTIR 7975, National Institute of Standards and Technology, November 2013.

[19]"Sustainable Manufacturing - A Business Perspective: A Technology Roadmap," University of Kentucky, Institute for Sustainable Manufacturing, Feb. 2015.

[20]International Organization for Standardization (ISO), http://www.iso.org.

[21]American Society for Mechanical Engineers, (ASME) https://www.asme.org

[22]ASTM International, http://astm.org

[23]American National Standards Institute (ANSI), http://ansi.org

[24]Open Source Initiative, http://opensource.org/osr-intro

[25]World Wide Web Consortium (W3C), http://www.w3.org

[26]Internet Engineering Task Force (IETF), http://ietf.org

[27]ISO 10303-1:1994, "Industrial automation systems and integration - Product data representation and exchange - Part 1: Overview and fundamental principles," International Organization for Standardization, 12/01/1994

[28]Open Applications Group Inc. (OAGi), http://www.oagi.org

[29]MTConnect Institute, http://mtconnect.org

[30]International Electrotechnical Commission (IEC), http://www.iec.ch

[31]OPC, https://opcfoundation.org

[32]Dimensional Metrology Standards Consortium (DMSC), http://www.dmsc-inc.org

[33]Manufacturing Enterprise Solutions Association International (MESA), http://mesa.org

[34]International Society of Automation (ISA), https://www.isa.org

[35]APICS, http://www.apics.org

[36]Industrial Internet Consortium (IIC), http://www.industrialinternetconsortium.org

[37] Institute of Electrical and Electronics Engineers (IEEE), http://www.ieee.org

[38]The Object Management Group, http://www.omg.org/

[39]NIST, Enabling the Digital Thread for Smart Manufacturing, http://www.nist.gov/el/msid/infotest/digital-thread-manufacturing.cfm

[40]NIST, Model-Based Enterprise Summit 2014, http://www.nist.gov/el/msid/mbesummit 2014.cfm

[41]National Institute of Standards and Technology (NIST), http://www.nist.gov

[42]NIST Big Data Program, http://bigdatawg.nist.gov/

[43]NIST Cybersecurity Framework, http://www.nist.gov/cyberframework

[44]www.manufacturing.gov

[45]G. Vogel-Heuser, G. Kegel, K. Bender, and K. Wucherer, Global information architecture for industrial automation. Automatisierungstechnische Praxis (atp), Oldenbourg-Verlag, Muenchen, 2009.

[46]https://www.whitehouse.gov/omb/circulars_a119/\#3

[47]K. Amoako-Gyampah, M. Acquaah, Manufacturing strategy, competitive strategy and firm performance: An empirical study in a developing economy environment - International Journal of Production Economics, 2008

[48]STEP AP242 Project, www.ap242.org

[49]Encyclopedia Britannica. In Encyclopedia Britannica Online: http:// www.britannica.com, 2015

[50]Rajesh ATTRI, Sandeep GROVER, A comparison of production system life cycle models, Front. Mech. Eng. 2012, 7(3): 305-311 
[51]J. Lubell,S.P. Frechette, R.R. Lipman, F.M. Proctor, J.A. Horst, M. Carlisle,P.J. Huang, 2013. ModelBased Enterprise Summit Report, NIST Technical Note 1820, U.S. Department of Commerce

[52]A. Barnard Feeney, S.P. Frechette, V. Srinivasan; "A portrait of an ISO STEP tolerancing standard as an enabler of smart manufacturing systems;" 13th CIRP Conference on Computer Aided Tolerancing; May 2014;

[53]A.V. Euler-Chelpin, Information modelling for the manufacturing system life cycle, Doctoral Thesis, KTH Royal Institute of Technology, Stockholm, Sweden, 2008

[54]K. Thramboulidis, IEC 61499 vs. 61131: A Comparison Based on Misperceptions, ournal of software engineering and applications 6(08), December, 2012

[55]VDI/VDE-Gesellschaft Mess und Automatisierungstechnik (GMA). Cyber-physical systems: Chancen und nutzen aus sicht der Automation, Thesen und Handlungsfelder, April 2013.

[56] Germany Trade and Invest, Industrie 4.0 Smart Manufacturing for the Future, http://www.gtai.de/GTAI/Content/EN/Invest/_SharedDocs/Downloads/GTAI/Brochures/Industries/in dustrie4.0-smart-manufacturing-for-the-future-en.pdf

[57]Recommendations for implementing the strategic initiative INDUSTRIE 4.0, http://www.acatech.de/fileadmin/user upload/Baumstruktur nach Website/Acatech/root/de/Mater ial fuer Sonderseiten/Industrie 4.0/Final report Industrie 4.0 accessible.pdf

[58]The Reference Architectural Model Industrie 4.0 (RAMI 4.0), http://www.zvei.org/Downloads/Automation/ZVEI-Industrie-40-RAMI-40-English.pdf

[59]Connecting machines, loT and the Cloud, http://www.iec.ch/etech/2015/etech 0515/ind-1.htm, May 2015.

[60]K. Bledowski, The Internet of Things: Industrie 4.0 vs. the Industrial Internet https://www.mapi.net/research/publications/industrie-4-0-vs-industrial-internet, June, 2015.

[61]Open Interconnect Consortium, http://openinterconnect.org/

[62]Internet of Things Architecture, http://www.iot-a.eu/public

[63]https://www.iot-at-work.eu/index.html

[64]ETSI, Machine to Machine Communications, http://www.etsi.org/index.php/technologiesclusters/technologies/m2m

[65]M2M World news, Standards will be critical for the emergence of the Internet of Things, http://m2mworldnews.com/2014/07/31/80797-standards-will-be-critical-for-the-emergence-of-theinternet-of-things/, 2014

[66]OneM2M, http://www.onem2m.org/

[67]Open Mobile Alliance, http://openmobilealliance.org/about-oma/work-program/m2m-enablers/

[68]Eclipse loT, http://iot.eclipse.org/standards

[69]HyperCat, http://www.hypercat.io/

[70]Weightless, http://www.weightless.org/

[71]Eclipse SCADA, http://www.eclipse.org/eclipsescada/

[72]NIST, Cyber-Physical Systems, http://www.nist.gov/cps/

[73]H2020 call1 2014 - topic ICT1 "Smart Cyber-Physical Systems" - Overview of selected projects, http://ec.europa.eu/digital-agenda/en/news/h2020-call1-2014-topic-ict1-smart-cyber-physicalsystems-overview-selected-projects

[74]VDI, Fachausschuss 7.20 - Cyber-Physical Systems, https://www.vdi.de/technik/fachthemen/messund-automatisierungstechnik/fachbereiche/anwendungsfelder-der-automation/gma-fa-720-cyberphysical-systems/

[75]MESA, Smart Manufacturing Working Group, http://mesa.org/en/committeeactivities/smartmanufacturingworkinggroup.asp

[76]Smart Manufacturing Leadership Coalition, https://smartmanufacturingcoalition.org/ 
[77]NIST Workshop on Open Cloud Architectures for Smart Manufacturing, http://www.nist.gov/el/msid/opencloudarch.cfm

[78]Lydon, B., Automation \& Control Trends in 2015, http://www.automation.com/automationnews/article/automation-control-trends-in-2015

[79]IPC, http://ipc.org

[80]Accenture, How the industrial internet is changing the competitive landscape of industries, https://www.accenture.com/us-en/insight-industrial-internet-competitive-landscape-industries.aspx

[81]ProSTEP iViP Association, http://www.prostep.org/nc/en.html

[82]ANSI, http://www.ansi.org/news publications/news story. aspx?menuid=7\&articleid=1862af9b-715744fa-b43b-ee3b3e9029ba

[83]B. Roben, Standards Activities of Organizations in the United States, NIST Special Publication 806, 1996 Edition.

[84]Arden L. Bement, "Standards and Infrastructure: Foundations of Manufacturing Competitiveness", http://www.nist.gov/director/speeches/bement 032703.cfm

[85] Overview of the U.S. Standardization System, http://www.standardsportal.org/usa en/standards system.aspx

[86]The Empirical Economics of Standards JUNE 2005, DTI Economics Paper no.12, June 2005, http://www.sis.se/upload/632555702720125533.pdf

[87]Economic Benefits of Standardization , DIN - German Institute for Standardization, 2000, http://www.din.de/blob/89552/68849fab0eeeaafb56c5a3ffee9959c5/economic-benefits-ofstandardization-en-data.pdf

[88]Standards Learn, http://www.standardslearn.org/

[89]T. J. Coelli, D. S. P. Rao, C.J. O'Donnell, G.E. Battese, An Introduction to Efficiency and Productivity Analysis, Springer, 2005

[90] A. V. Euler-Chelpin, Information modelling for the manufacturing system life cycle, Doctoral Thesis, KTH - Production Engineering, Stockholm, Sweden, 2008, ISSN 1650-1888

[91]A. Zuckerman, International Standards Desk Reference: Your Passport to World Markets, American Management Association, 1997

[92] https://www.modelica.org/

[93]The Data Mining Group, http://dmg.org/

[94]Global Harmonization of Standards, http://www.okstate.edu/ind-engr/step/WEBFILES/Papers/ Global Harm body.htm

[95]NIST Smart Manufacturing Systems Design and Analysis Program, http://www.nist.gov/el/msid/ syseng/smsda.cfm

[96]NIST Robotic Systems for Smart Manufacturing Program, http://www.nist.gov/el/isd/ms/rssm.cfm

[97]NIST Measurement Science for Additive Manufacturing Program, http://www.nist.gov/el/isd/ $\underline{\mathrm{sbm} / \mathrm{msam} . \mathrm{cfm}}$ 